\title{
Implementation of dust emission and chemistry into the Community Multiscale Air Quality modeling system and initial application to an Asian dust storm episode
}

\author{
K. Wang ${ }^{1}$, Y. Zhang ${ }^{1,2}$, A. Nenes ${ }^{3,4,5}$, and C. Fountoukis ${ }^{5}$ \\ ${ }^{1}$ Department of Marine, Earth, and Atmospheric Sciences, North Carolina State University, Campus Box 8208, Raleigh, \\ NC 27695, USA \\ ${ }^{2}$ School of Environment, Tsinghua University, Beijing, China \\ ${ }^{3}$ School of Earth and Atmospheric Sciences, Georgia Institute of Technology, Atlanta, GA 30332, USA \\ ${ }^{4}$ School of Chemical and Biomolecular Engineering, Georgia Institute of Technology, Atlanta, GA 30332, USA \\ ${ }^{5}$ Institute of Chemical Engineering and High Temperature Chemical Processes (ICE-HT), Foundation for Research and \\ Technology Hellas (FORTH), Patras, 26504, Greece
}

Correspondence to: Y. Zhang (yzhang9@ @ ncsu.edu)

Received: 19 April 2012 - Published in Atmos. Chem. Phys. Discuss.: 31 May 2012

Revised: 2 October 2012 - Accepted: 5 October 2012 - Published: 6 November 2012

\begin{abstract}
The US Environmental Protection Agency's (EPA) Community Multiscale Air Quality (CMAQ) modeling system version 4.7 is further developed to enhance its capability in simulating the photochemical cycles in the presence of dust particles. The new model treatments implemented in CMAQ v4.7 in this work include two online dust emission schemes (i.e., the Zender and Westphal schemes), nine dust-related heterogeneous reactions, an updated aerosol inorganic thermodynamic module ISORROPIA II with an explicit treatment of crustal species, and the interface between ISORROPIA II and the new dust treatments. The resulting improved CMAQ (referred to as CMAQ-Dust), offlinecoupled with the Weather Research and Forecast model (WRF), is applied to the April 2001 dust storm episode over the trans-Pacific domain to examine the impact of new model treatments and understand associated uncertainties. WRF/CMAQ-Dust produces reasonable spatial distribution of dust emissions and captures the dust outbreak events, with the total dust emissions of $\sim 111$ and $223 \mathrm{Tg}$ when using the Zender scheme with an erodible fraction of 0.5 and 1.0, respectively. The model system can reproduce well observed meteorological and chemical concentrations, with significant improvements for suspended particulate matter (PM), PM with aerodynamic diameter of $10 \mu \mathrm{m}$, and aerosol optical depth than the default CMAQ v4.7. The sensitivity studies
\end{abstract}

show that the inclusion of crustal species reduces the concentration of PM with aerodynamic diameter of $2.5 \mu \mathrm{m}\left(\mathrm{PM}_{2.5}\right)$ over polluted areas. The heterogeneous chemistry occurring on dust particles acts as a sink for some species (e.g., as a lower limit estimate, reducing $\mathrm{O}_{3}$ by up to $3.8 \mathrm{ppb}(\sim 9 \%)$ and $\mathrm{SO}_{2}$ by up to $\left.0.3 \mathrm{ppb}(\sim 27 \%)\right)$ and as a source for some others (e.g., increasing fine-mode $\mathrm{SO}_{4}^{2-}$ by up to $1.1 \mu \mathrm{g} \mathrm{m}^{-3}$ $(\sim 12 \%)$ and $\mathrm{PM}_{2.5}$ by up to $\left.1.4 \mu \mathrm{g} \mathrm{m}^{-3}(\sim 3 \%)\right)$ over the domain. The long-range transport of Asian pollutants can enhance the surface concentrations of gases by up to $3 \%$ and aerosol species by up to $20 \%$ in the Western US.

\section{Introduction}

Natural and anthropogenic aerosols are known to play a significant role in human health, climate change, atmospheric visibility, stratospheric ozone depletion, acid deposition, and photochemical smog. The role of natural aerosols on air quality and climate is as significant as that of anthropogenic aerosols, not only because of their very high global mass loading (probably 4 to 5 times larger than that of anthropogenic aerosols on a global scale according to Satheesh and Moorthy, 2005), but also because of their contribution to the long-range transport as carriers and to atmospheric chemistry

Published by Copernicus Publications on behalf of the European Geosciences Union. 
as reaction sites. Among aerosols, mineral dust or soil dust is one of the major tropospheric aerosol components (IPCC, 2007). The uncertainties in direct and indirect atmospheric radiative forcing by mineral dust are considered to be one of the largest ones in climate and chemistry transport models. Therefore, an accurate modeling of mineral dust emissions, transport, and chemistry would enhance the understanding of dust storm episodes and their impacts on air quality and climate.

Dust storms have been simulated in numerous studies in the past decade. Although these studies were able to reproduce many observations and demonstrate characteristic transport patterns of dust storms (e.g., Westphal et al., 1987; Tegen and Fung, 1994; Marticorena and Bergametti, 1995; Mahowald et al., 1999; Ginoux et al., 2001; Nickovic et al., 2001; Shao, 2001; Uno et al., 2003; Zender et al., 2003; Darmenova et al., 2009; Shao et al., 2010; Spyrou et al., 2010; Kang et al., 2011; Solomos et al., 2011; Knippertz and Todd, 2012), there remain large uncertainties and discrepancies for various dust emission and transport models. The uncertainties are mainly from different model parameterizations of dust emission processes, estimated amounts of dust reaching remote areas during dust storm events, and variations in the size distribution during long-range transport. The discrepancies are mainly due to different treatments in dust emission schemes, different atmospheric transport models and resultant meteorological predictions (e.g., wind velocity), and land surface conditions (e.g., soil textures, soil wetness, and land use data).

In recent years, increasing research attention has been given to chemical composition and processes associated with dust particles. Numerous experimental (e.g., Goodman et al., 2000; Underwood et al., 2001; Li et al., 2006; Song et al., 2007; Ndoru et al., 2008, 2009; Wagner et al., 2008; McNaughton et al., 2009; Crowley et al., 2010; Li et al., 2010; Tang et al., 2010) and modeling studies (Zhang et al., 1994; Dentener et al., 1996; Zhang and Carmichael, 1999; Underwood et al., 2001; Bian and Zender, 2003; Bauer et al., 2004; Liao and Seinfeld, 2005; Tie et al., 2005; Pozzoli et al., 2008a, b; Astitha et al., 2010; Manktelow et al., 2010; Zhu et al., 2010; Karydis et al., 2011) have demonstrated the significance of heterogeneous chemistry on the surface of mineral dust particles in altering the concentration of atmospheric gaseous and aerosol compositions. For example, using a box model, Zhang et al. (1994) reported that the heterogeneous reaction on the surface of mineral dust can reduce nitrogen oxides $\left(\mathrm{NO}_{\mathrm{x}}\right)$ levels by up to $50 \%$, hydroperoxyl radical $\left(\mathrm{HO}_{2}\right)$ concentrations by 20 to $80 \%$, and ozone $\left(\mathrm{O}_{3}\right)$ production rates by up to $25 \%$ with the dust level of 0 to $500 \mu \mathrm{g} \mathrm{m}^{-3}$. Using a global model, Dentener et al. (1996) found that the interactions of dinitrogen pentoxide $\left(\mathrm{N}_{2} \mathrm{O}_{5}\right)$, $\mathrm{O}_{3}$, and $\mathrm{HO}_{2}$ radicals with dust can affect the photochemical oxidants cycle and cause $\mathrm{O}_{3}$ decreases by up to $10 \%$ near the dust source regions where dust mass concentrations are more than $300 \mu \mathrm{g} \mathrm{m}^{-3}$. Using another global model, Pozzoli et al. (2008a) also found that heterogeneous chemistry significantly reduced the distributions of a number of key gases such as $\mathrm{O}_{3}$ by 18 to $23 \%$ over the trans-Pacific region and nitric acid $\left(\mathrm{HNO}_{3}\right)$ by $15 \%$ globally. Li et al. (2006) showed in their laboratory study that atmospheric sulfur dioxide $\left(\mathrm{SO}_{2}\right)$ loss via the heterogeneous reaction on dust is comparable to loss via the gas-phase oxidation under high dust conditions (i.e., when the number concentrations of dust are $\sim 8$ to $\left.56 \mathrm{~cm}^{-3}\right)$.

The US Environmental Protection Agency's (EPA) Community Multiscale Air Quality (CMAQ) modeling system version 4.4 has been previously applied by Wang et al. (2009) over the trans-Pacific domain to study the long-range transport of Asian air pollutants and its impact on regional air quality over North America. CMAQ reasonably reproduces observed mass concentrations of most air pollutants and captures their transport mechanisms. It, however, is incapable of reproducing observed mass concentrations of particulate matter with aerodynamic diameter less than or equal to $10 \mu \mathrm{m}$ $\left(\mathrm{PM}_{10}\right)$ and aerosol optical depths (AODs), due to the lack of mineral dust treatments in CMAQ (Wang et al., 2009; Wang and Zhang, 2010). In this study, this limitation is addressed by implementing an online dust emission and heterogeneous chemistry module into CMAQ version 4.7 in order to investigate the role of dust in affecting chemical predictions of air pollutants. In addition, the default inorganic thermodynamic equilibrium module ISORROPIA 1.7 (Nenes et al., 1998, 1999) in CMAQ v4.7 is updated to ISORROPIA II (Fountoukis and Nenes, 2007; Fountoukis et al., 2009) to account for the thermodynamic interactions of dust with other chemical species. The version of CMAQ with the above new treatments (referred to hereafter as CMAQ-Dust) is then applied to the April 2001 Intercontinental transport and Climatic effects of Air Pollutants (ICAP) episode to investigate dust transport, the role of dust in affecting chemical predictions of air pollutants, and the impact of the associated crustal species (e.g., calcium $(\mathrm{Ca})$, potassium $(\mathrm{K})$, and magnesium $(\mathrm{Mg}))$ on the inorganic gas/particle partitioning through the aerosol thermodynamic equilibrium. The objective of study is to enhance the capability of CMAQ to simulate PM and its interactions with photochemical cycles, as well as long-range transport of air pollutants associated with dust storms.

In the next section, a detailed description of the new dust emission and chemistry treatments in CMAQ-Dust is presented. Section 3 presents model configurations and simulation setup. Section 4 describes the model performance evaluation of meteorological and chemical variables. Section 5 examines the impacts of dust treatments on model predictions. Major findings, limitations, and future improvements are summarized in Sect. 6. 


\section{The development of CMAQ-Dust}

\subsection{Online dust emission module}

Dust emissions are favored by strong ground-level winds associated with large-scale disturbances or convective activity. Dust mobilization is often inhibited by surface-covering elements such as vegetation, snow cover, and rocks. It is also constrained by soil conditions such as high soil moisture and high salinity. With these factors, active mineral dustproducing surfaces are normally confined to "bare ground" or "sparsely vegetated ground" in arid and semiarid regions with strong winds (Tanaka, 2007; Yue et al., 2009). Parameterizations of dust fluxes often take into consideration the aforementioned factors, though the formulation varies considerably among mathematical expressions.

Various dust mobilization/flux schemes used in 3-D atmospheric models have been reviewed in several studies (e.g., Zender et al., 2003; Shao and Dong, 2006; Chervenkov and Jakobs, 2011). They can be grouped based on the complexity of schemes. For example, Zender et al. (2003) classified dust schemes in three "complexity" groups. In the "simple" treatments, the emission of dust is parameterized in terms of the third or fourth power of the wind speed or friction speed and the emitted dust is then redistributed empirically based on an assumption of size distribution (Westphal et al., 1987; Tegen and Fung, 1994; Mahowald et al., 1999). Under this assumption, different sizes of particles have the same emission rates and very detail microphysical information (e.g., the soil particle size distribution over different source regions) is not necessary. In "complex" dust emission schemes, a complete microphysical parameterization is used to predict the sizeresolved saltation mass flux and resulting sandblasted dust emissions (Marticorena and Bergametti, 1995; Shao, 2001; Shao et al., 2010). In this case, different sizes of dust particles have different emission rates. Although these schemes provide the most physically based approach for estimating dust emissions, many input parameters/information are not available to constrain them, especially for large-scale simulations. Nevertheless, this class of schemes has shown some promising results in regional simulations (Marticorena and Bergametti, 1995; Darmenova et al., 2009; Kang et al., 2011). "Intermediate" complexity schemes use microphysical parameterizations wherever possible, but invoke simplified assumptions to allow their application in large-scale/global simulations (Ginoux et al., 2001; Zender et al., 2003). All the above schemes have been favorably evaluated against lab and/or field experiments. Table 1 summarizes the main characteristics of several major dust flux schemes mentioned above.

In this study, two established and commonly used dust flux schemes are adapted and incorporated into CMAQ v4.7: the Westphal et al. (1987) scheme with modifications by Choi and Fernando (2008) (hereafter called "Westphal scheme") and the Zender et al. (2003) scheme (hereafter called "Zender scheme"). A major difference between the two schemes is that the Zender scheme splits the dust flux into two components, horizontally saltating mass flux of large particles $\left(Q_{\mathrm{s}}\right)$ and vertical mass flux of dust $\left(F_{\mathrm{d}}\right)$, whereas the Westphal calculates vertical fluxes directly. Even if the Zender scheme is more physically based than the Westphal scheme, incorporating both approaches in CMAQ-Dust permits an assessment of the sensitivity of dust emissions and impacts on different dust flux parameterizations. A detailed description about these two schemes is given below.

The Westphal scheme is based on the assumption that the vertical mass fluxes of dust particles with radius less than $10 \mu \mathrm{m}$ can be expressed as a function of surface friction velocity $\left(u_{*}\right)$; data to constrain the parameterization are based on measurements from Sahara, the Southwestern US, and Israeli deserts. The associated formulas for the dust vertical flux, $F_{\mathrm{d}}\left(\mathrm{g} \mathrm{m}^{-2} \mathrm{~s}^{-1}\right)$, are expressed as

$F_{\mathrm{d}}=E_{\mathrm{F}} \times\left(1-R_{\mathrm{F}}\right) \times C \times u_{*}^{3} \times H$

where $H$ is the Heaviside function that depends on $u_{*}-u_{* \mathrm{t}}$. $u_{*}$ is the surface friction velocity, and $u_{* \mathrm{t}}$ is the threshold surface friction velocity. $H=1$ when $u_{*}-u_{* t} \geq 0$, indicating that dust particles can only be emitted from the surface under such conditions. $H=0$ when $u_{*}-u_{* \mathrm{t}}<0$, indicating no dust emissions. $C$ is $10^{-13}$ and $10^{-14} u_{*}$ for predominantly sandy and silt/clay soil, respectively. $R_{\mathrm{F}}$ is a reduction factor over different land types based on the 24 US Geophysical Survey (USGS) land use categories; in this study, we consider three land use category types (Choi and Fernando, 2008): shrubland $\left(R_{\mathrm{F}}=0.7\right)$, mixed shrub/grassland $\left(R_{\mathrm{F}}=0.75\right)$, and barren/sparsely vegetated land $\left(R_{\mathrm{F}}=0.1\right) . E_{\mathrm{F}}$ is an adjustable parameter that represents the fraction of erodible lands capable of emitting dust. Although $E_{\mathrm{F}}$ may vary with locations due to heterogeneity of the erodibility of the lands, Liu and Westphal (2001) suggested a constant value of 0.13 , which was based on the land surface conditions in 1950s (Clements et al., 1957). More recent studies (Liu et al., 2003; Yang et al., 2005) suggested higher values should be used for current conditions over arid areas, indicating that this factor should be adjusted based on current land conditions and may vary with locations and episodes. Three values, $0.3,0.5$, and 1.0, are therefore selected, to test its sensitivity to dust emissions. The results with $E_{\mathrm{F}}=0.5$ and 1.0 are shown in the following sections. In the original scheme of Westphal et al. (1987), they assumed a constant value of $u_{* t}$, which is subject to high uncertainties for larger-scale simulation. Recently, Choi and Fernando (2008) improved the scheme by considering the effects of soil texture (i.e., soil percentage of sand, silt, and clay) and soil moisture on $u_{* \mathrm{t}}$, which makes the scheme more suitable for larger-scale study. In addition to the soil texture and moisture, there are several other factors that may affect the values of $u_{* t}$, such as the particle size distribution of soils and the drag partitioning between the traditional aerodynamic roughness length and "smooth" roughness length (Marticorena and Bergametti, 1995). The aerodynamic roughness length of the bare ground includes 
Table 1. Similarities and differences of several major dust flux schemes.

\begin{tabular}{|c|c|c|c|c|c|}
\hline \multirow{2}{*}{$\begin{array}{l}\text { Complexity } \\
\text { Example } \\
\text { references }\end{array}$} & \multicolumn{2}{|c|}{ Simple } & \multicolumn{2}{|c|}{ Intermediate } & \multirow{2}{*}{$\begin{array}{l}\text { Advanced } \\
\text { Marticorena and } \\
\text { Bergametti (1995) }\end{array}$} \\
\hline & $\begin{array}{l}\text { Westphal et al. } \\
(1987) ; \text { Liu and } \\
\text { Westphal (2001) }\end{array}$ & $\begin{array}{l}\text { Choi and Fernando } \\
\text { (2008) }\end{array}$ & $\begin{array}{l}\text { Ginoux et al. } \\
(2001)\end{array}$ & Zender et al. (2003) & \\
\hline Flux calculation ${ }^{\mathrm{a}}$ & $\begin{array}{l}\text { Vertical flux; } u_{*}^{3} \\
\text { and } u_{*}^{4}\end{array}$ & $\begin{array}{l}\text { Vertical flux; } u_{*}^{3} \text { or } \\
u_{*}^{4}\end{array}$ & $\begin{array}{l}\text { Horizontal flux; } \\
u_{10}^{3} \text { and } u_{\mathrm{t}}\end{array}$ & $\begin{array}{l}\text { Horizontal flux and } \\
\text { vertical flux; } u_{*}^{3} \text { and } \\
u_{* \mathrm{t}}\end{array}$ & $\begin{array}{l}\text { Horizontal flux and } \\
\text { vertical flux; } u_{*}^{3} \text { and } \\
u_{* \mathrm{t}}\end{array}$ \\
\hline $\begin{array}{l}\text { Factors affecting } \\
u_{* \mathrm{t}}\end{array}$ & Constant & $\begin{array}{l}\text { Soil texture } \\
\text { and moisture }\end{array}$ & $\begin{array}{l}\text { Soil particle size, } \\
\text { density, and } \\
\text { moisture }\end{array}$ & $\begin{array}{l}\text { Soil particle size, } \\
\text { density, } \\
\text { moisture, and } \\
\text { surface roughness }\end{array}$ & $\begin{array}{l}\text { Soil particle size, } \\
\text { density, } \\
\text { moisture, and } \\
\text { surface roughness }\end{array}$ \\
\hline $\begin{array}{l}\text { Dependency on the } \\
\text { particle sizes }\end{array}$ & No & No & $\begin{array}{l}\text { Yes, different size } \\
\text { bins }\end{array}$ & $\begin{array}{l}\text { Yes, but assume a } \\
\text { constant }\end{array}$ & $\begin{array}{l}\text { Yes, continuous for } \\
\text { any size }\end{array}$ \\
\hline $\begin{array}{l}\text { Topographic } \\
\text { consideration }\end{array}$ & No & No & Yes & Yes & No \\
\hline $\begin{array}{l}\text { Erodible flux } \\
\text { fraction } \\
\text { consideration }\end{array}$ & $\begin{array}{l}\text { Yes; based on land } \\
\text { types }\end{array}$ & $\begin{array}{l}\text { Yes; based on land } \\
\text { types }\end{array}$ & $\begin{array}{l}\text { Yes; based on soil } \\
\text { texture }\end{array}$ & $\begin{array}{l}\text { Yes; based on } \\
\text { roughness length }\end{array}$ & $\begin{array}{l}\text { Yes; based on } \\
\text { roughness length }\end{array}$ \\
\hline Host 3-D Models b & COAMPS & CMAQ & GOCART & GEOS-Chem & N/A \\
\hline
\end{tabular}

the nonerodible elements such as pebbles, rocks, and vegetation, and the "smooth" roughness length only represents potentially erodible particles without any nonerodible elements. The latter is typically less than the former, and the resulting drag partitioning will increase the values of $u_{* \mathrm{t}}$. In the current version of emission scheme, only the soil moisture and texture are considered due to the lack of other information. In applying the parameterization, an initial value of $u_{* \mathrm{t}}, u_{* \mathrm{tI}}$, is first determined by the Marticorena et al. (1997) expression, being $0.43,0.43$, and $0.30 \mathrm{~m} \mathrm{~s}^{-1}$ for shrubland, mixed shrub/grassland, and barren/sparsely vegetated land, respectively. An updated value of $u_{* \mathrm{t}}$ is then calculated using the following empirical formula (Fecan et al., 1999):

$u_{* \mathrm{t}}=u_{* \mathrm{tI}}\left[1+121\left(\max \left(w-w^{\prime}, 0\right)\right)^{0.68}\right]^{0.5}$

where $w$ is the gravimetric soil moisture $\left(\mathrm{kg} \mathrm{kg}^{-1}\right)$ and $w^{\prime}$ is the threshold gravimetric soil moisture and determined by the following empirical formulations (Fecan et al., 1999; Zender et al., 2003):

$w=\theta \rho_{\mathrm{w}} / \rho_{\mathrm{p}, \mathrm{d}}$

$\rho_{p, d}=\rho_{\mathrm{p}}\left(1.0-\theta_{\mathrm{s}}\right)$

$\theta_{\mathrm{s}}=0.489-0.126 M_{\text {sand }}$ $w^{\prime}=14 M_{\text {clay }}^{2}+17 M_{\text {clay }}$

where $\theta$ is the volumetric soil moisture $\left(\mathrm{m}^{3} \mathrm{~m}^{-3}\right)$ from the National Centers for Environmental Prediction (NCEP)/National Center for Atmospheric Research (NCAR) reanalysis data, $\rho_{\mathrm{w}}=1000 \mathrm{~kg} \mathrm{~m}^{-3}$ is the density of water, $\rho_{\mathrm{p}}=2600 \mathrm{~kg} \mathrm{~m}^{-3}$ is the mean soil particle density, $\rho_{\mathrm{p}, \mathrm{d}}$ is the bulk density of dry soil, $\theta_{\mathrm{s}}$ is volumetric saturation soil moisture $\left(\mathrm{m}^{3} \mathrm{~m}^{-3}\right)$, and $M_{\text {sand }}$ and $M_{\text {clay }}$ are the mass fractions of sand and clay, respectively, in the soil.

The dust emission parameterization of Zender et al. (2003) has been extensively used in global modeling studies (e.g., Liao and Seinfeld, 2005; Fairlie et al., 2007, 2010; Nowottnick et al., 2010). In this scheme, $Q_{\mathrm{s}}\left(\mathrm{g} \mathrm{m}^{-1} \mathrm{~s}^{-1}\right)$ is expressed as a function of $u_{*}$ and $u_{* \mathrm{t}}$ according to the theory of Kawamura (1964) and White (1979). The formulas are as follows:

$$
Q_{\mathrm{s}}=E_{\mathrm{F}} \frac{c_{\mathrm{s}} \rho u_{*}^{3}}{g}\left(1-\frac{u_{* \mathrm{t}}^{2}}{u_{*}^{2}}\right)\left(1+\frac{u_{* \mathrm{t}}}{u_{*}}\right) H
$$

where $c_{\mathrm{S}}$ is an empirical constant with a value of 2.61, $\rho$ is the atmospheric density, and $g$ is acceleration of gravity. Different from the Westphal scheme, $u_{* \mathrm{tI}}$ is determined by the semi-empirical relationship of Iversen and White (1982): 


$$
\begin{aligned}
& u_{* \mathrm{tI}}(D)=\left[\frac{0.1666681 \rho_{\mathrm{p}} g D}{1.928 R e_{* \mathrm{t}}^{0.0922}-1}\left(1+\frac{6 \times 10^{-7}}{\rho_{\mathrm{p}} g D^{2.5}}\right)\right]^{1 / 2} \rho^{-1 / 2} \\
& \text { when } 0.03 \leq R e_{* \mathrm{t}} \leq 10 \\
& u_{* \mathrm{tI}}(D)=\left[0.0144 \rho_{\mathrm{p}} g D\left(1-0.0858 e^{-0.0617\left(R e_{* \mathrm{t}}-10\right)}\right)\right. \\
& \left.\left(1+\frac{6 \times 10^{-7}}{\rho_{\mathrm{p}} g D^{2.5}}\right)\right]^{1 / 2} \rho^{-1 / 2} \text { when } R e_{* \mathrm{t}}>10
\end{aligned}
$$

where $\rho_{\mathrm{p}}$ is the mean soil particle density, $D$ is the average diameter of saltation particles and is assumed to be the optimal particle size, $D_{0} \approx 75 \mu \mathrm{m}$, under typical conditions on Earth (Zender et al., 2003). $R e_{* \mathrm{t}}$ is the threshold friction Reynolds number and is estimated using an empirical expression introduced by Marticorena and Bergametti (1995):

$R e_{* \mathrm{t}}=1331 D^{1.56}+0.38$

Following Zender et al. (2003), $R e_{* \mathrm{t}}$ is assumed to be a fixed value due to a constant value of $D$ (i.e., $75 \mu \mathrm{m}$ ) in this study. An updated spatially varied value of $u_{* \mathrm{t}}$ is calculated based on $u_{* \mathrm{II}}$ from Eqs. (8)-(9) and Eqs. (2)-(6) accounting for the effects of soil moisture. The horizontal saltation mass flux $Q_{\text {s }}$ is then converted to a vertical dust mass flux $F_{\mathrm{d}}$ (the final dust flux in the Zender scheme and in units of $\mathrm{g} \mathrm{m}^{-2} \mathrm{~s}^{-1}$ ) by

$F_{\mathrm{d}}=T \times S \times \alpha \times Q_{\mathrm{s}}$

where $T$ is a global tuning factor and is set to be $T=$ $7.0 \times 10^{-4}$, following Zender et al. (2003), $S$ is the "source erodibility" factor with values from 0 to 1 from the database provided by Ginoux et al. (2001) and confines dust emissions to topographic depressions in desert and semi-desert areas of the world. $\alpha$ is the sandblasting mass efficiency in the unit of $\mathrm{m}^{-1}$ that converts horizontal mass flux to vertical dust flux and empirically parameterized based on Marticorena and Bergametti (1995):

$\alpha=100 e^{\left[\left(13.4 \times \min \left(M_{\text {clay }}, 0.2\right)-6.0\right) \times \ln 10\right]}$

where $M_{\text {clay }}$ is the mass fraction of clay particles in parent soil.

The soil texture data used for both schemes are taken from the US State Soil Geographic (STATSGO)/Food and Agriculture Organization of the United Nations (FAO) soil database with a $1-\mathrm{km}$ grid resolution. $u_{*}$ directly comes from a meteorological model. The land use data used in this study are the dominant land use category in each grid cell. This information is taken from the USGS dataset at a $1-\mathrm{km}$ grid resolution and is gridded to the domain in this study using the WRF Preprocessing System (WPS) utility. The simulated snow cover and precipitation data are used for determining whether the dust emissions will be generated over each grid cell of the simulation domain. Nickovic et al. (2001) have classified the particle sizes of mineral dust into four categories based on the contents of clay, small silt, large silt, and sand. Only the first two types, clay and small silt, are considered as $\mathrm{PM}_{10}$. In this way, the dust flux generated from Eqs. (1) and (11) is further multiplied by a fraction, which is based on the STATSGO soil texture data to approximate the fluxes of dust $\mathrm{PM}_{10}$ in a given grid cell (Choi and Fernando, 2008). According to Midwest Research Institute (2005), the $\mathrm{PM}_{2.5} / \mathrm{PM}_{10}$ ratio for typical fugitive dust sources is 0.1 , so the fluxes of dust $\mathrm{PM}_{2.5}$ can be obtained by multiplying the fluxes of dust $\mathrm{PM}_{10}$ by 0.1 .

\subsection{Heterogeneous chemistry on the surface of dust particles}

Table 2 presents the nine heterogeneous reactions assumed to occur on the surfaces of dust. Absorption and heterogeneous reactions of gases on the surfaces of dust are assumed to be irreversible (Zhang and Carmichael, 1999). Following the method of Schwartz (1986), the uptake of gases onto the mineral dust particles is defined by a pseudo-first-order heterogeneous rate constant $K_{i}\left(\mathrm{~s}^{-1}\right)$ for species $i$ as follows:

$K_{i}=\left(\frac{d_{\mathrm{p}}}{2 D_{i}}+\frac{4}{v_{i} \gamma_{i}}\right)^{-1} S_{\mathrm{p}}$

where $d_{\mathrm{p}}$ is the dust particle diameter $(\mathrm{m}), D_{i}$ is the gasphase molecular diffusion coefficient for species $i\left(\mathrm{~m}^{2} \mathrm{~s}^{-1}\right)$, $v_{i}$ is the mean molecular velocity of species $i\left(\mathrm{~m} \mathrm{~s}^{-1}\right), S_{\mathrm{p}}$ is the surface area density of dust particles $\left(\mathrm{m}^{2} \mathrm{~m}^{-3}\right)$ and is determined from CMAQ simulation, and $\gamma_{i}$ is the uptake coefficient for species $i$. The uptake coefficients are largely based on the work of Bian and Zender (2003) and summarized in Table 2. The uncertainties in $\gamma_{i}$ are very large and can be more than three orders of magnitude for certain species (Zhang and Carmichael, 1999; Bian and Zender, 2003). For example, some studies have reported the values of $\gamma$ ranging from $2.0 \times 10^{-6}$ to $2.5 \times 10^{-3}$ for $\mathrm{O}_{3}$ and from $2.0 \times 10^{-6}$ to $1.6 \times 10^{-2}$ for $\mathrm{HNO}_{3}$ (Goodman et al., 2000; Underwood et al., 2001; Michel et al., 2002). Two sets of $\gamma$ values representing the lower and upper limit values, respectively, as shown in Table 2 are therefore tested in this study based on published values (Zhang and Carmichael, 1999; Bian and Zender, 2003; Zhu et al., 2010). A recent work by Crowly et al. (2010) also recommended several uptake coefficients of species on dust particles treated in this study, most of which are smaller than the lower limit (e.g., $\mathrm{O}_{3}, \mathrm{NO}_{2}, \mathrm{NO}_{3}$, and $\mathrm{SO}_{2}$ ) or between the lower and upper limits (e.g., $\mathrm{H}_{2} \mathrm{O}_{2}$ and $\mathrm{N}_{2} \mathrm{O}_{5}$ ) that are tested in this work. Consequently, the uptake coefficients recommended by Crowly et al. (2010) would lead to much less surface uptake and loss for most gaseous species and thus less production of $\mathrm{SO}_{4}^{2-}$ and $\mathrm{NO}_{3}^{-}$, as compared to the upper limit values used in this work. Most previous studies considering the uptake of $\mathrm{HNO}_{3}$ onto 
Table 2. Reactions and uptake coefficients considered in this study (modified from Bian and Zender, 2003).

\begin{tabular}{|c|c|c|c|c|}
\hline Species & Reactions & $\begin{array}{l}\text { Uptake coefficients, } \gamma \\
\text { (lower limit) }\end{array}$ & $\begin{array}{l}\text { Uptake coefficients, } \gamma \\
\text { (upper limit) }\end{array}$ & References \\
\hline $\mathrm{H}_{2} \mathrm{O}_{2}$ & $\begin{array}{l}\mathrm{H}_{2} \mathrm{O}_{2}+\text { Dust } \rightarrow \text { Prod- } \\
\text { ucts }\end{array}$ & $1.0 \times 10^{-4}$ & $2 \times 10^{-3}$ & Dentener et al. (1996) \\
\hline $\mathrm{HNO}_{3}$ & $\begin{array}{l}\mathrm{HNO}_{3}+\text { Dust } \rightarrow \\
0.5 \mathrm{NO}_{3}^{-}+0.5 \mathrm{NO}_{\mathrm{x}}\end{array}$ & $1.1 \times 10^{-3}$ & 0.2 & $\begin{array}{l}\text { Dentener et al. (1996); } \\
\text { DeMore et al. (1997); } \\
\text { Underwood et } \\
\text { al. (2001) }\end{array}$ \\
\hline $\mathrm{HO}_{2}$ & $\begin{array}{l}\mathrm{HO}_{2}+\mathrm{Fe}(\mathrm{II}) \rightarrow \mathrm{Fe}(\mathrm{III}) \\
+\mathrm{H}_{2} \mathrm{O}_{2}\end{array}$ & 0.1 & 0.2 & $\begin{array}{l}\text { Dentener et al. (1996); } \\
\text { Zhang and Carmichael } \\
\text { (1999) }\end{array}$ \\
\hline $\mathrm{N}_{2} \mathrm{O}_{5}$ & $\mathrm{~N}_{2} \mathrm{O}_{5}+$ Dust $\rightarrow 2 \mathrm{NO}_{3}^{-}$ & $1.0 \times 10^{-3}$ & 0.1 & $\begin{array}{l}\text { Dentener et al. (1996); } \\
\text { DeMore et al. (1997) }\end{array}$ \\
\hline $\mathrm{NO}_{2}$ & $\mathrm{NO}_{2}+$ Dust $\rightarrow \mathrm{NO}_{3}^{-}$ & $4.4 \times 10^{-5}$ & $2 \times 10^{-4}$ & $\begin{array}{l}\text { Underwood et } \\
\text { al. (2001) }\end{array}$ \\
\hline $\mathrm{NO}_{3}$ & $\mathrm{NO}_{3}+$ Dust $\rightarrow \mathrm{NO}_{3}^{-}$ & 0.1 & 0.23 & $\begin{array}{l}\text { Seinfeld and Pandis } \\
\text { (2006); Zhang and } \\
\text { Carmichael (1999) }\end{array}$ \\
\hline $\mathrm{O}_{3}$ & $\mathrm{O}_{3}+$ Dust $\rightarrow$ Products & $5.0 \times 10^{-5}$ & $1 \times 10^{-4}$ & $\begin{array}{l}\text { Dentener et al. (1996); } \\
\text { Zhang and Carmichael } \\
\text { (1999) }\end{array}$ \\
\hline $\mathrm{OH}$ & $\mathrm{OH}+$ Dust $\rightarrow$ Products & 0.1 & 1 & $\begin{array}{l}\text { Zhang and Carmichael } \\
\text { (1999) }\end{array}$ \\
\hline $\mathrm{SO}_{2}$ & $\mathrm{SO}_{2}+$ Dust $\rightarrow \mathrm{SO}_{4}^{2-}$ & $1.0 \times 10^{-4}$ & $2.6 \times 10^{-4}$ & $\begin{array}{l}\text { Zhang and Carmichael } \\
\text { (1999) }\end{array}$ \\
\hline
\end{tabular}

dust assumed it to be an irreversible process. However, experimental evidence (Knipping and Dabdub, 2002; RiveraFigueroa et al., 2003; Ndor et al., 2009) suggests that the reaction of gaseous nitric oxide with $\mathrm{HNO}_{3}$ on surfaces may release photochemically active $\mathrm{NO}_{\mathrm{x}}$. This so-called "renoxification" process is also considered in this study.

\subsection{Incorporation of ISORROPIA II and crustal species treatment into CMAQ}

It has been shown that the consideration of crustal materials in predicting the partitioning of $\mathrm{NO}_{3}^{-}$and $\mathrm{NH}_{4}^{+}$, especially in areas where mineral dust comprises a significant portion of aerosols, is very important and can potentially improve model predictions (Jacobson, 1999; Moya et al., 2002; Fountoukis et al., 2009). The ISORROPIA II thermodynamic equilibrium module (Fountoukis and Nenes, 2007; http://nenes.eas.gatech.edu/ISORROPIA) includes the thermodynamics of crustal materials of $\mathrm{Ca}, \mathrm{K}$, and $\mathrm{Mg}$ based on the preexisting suite of components of the ISORROPIA model. The model determines the subsystem set of equilibrium equations and solves for the equilibrium state using the chemical potential method. ISORROPIA II uses pre- calculated tables of binary activity coefficients and water activities of pure salt solutions, which speeds up calculations significantly. ISORROPIA implemented in CMAQ also offers the ability to solve for the "reverse problem" and makes a metastable assumption, which assumes that only aqueousphase particles are formed.

Following the incorporation of the online dust emission module and dust-related heterogeneous chemistry, three new crustal species (i.e., $\mathrm{Ca}, \mathrm{K}$, and $\mathrm{Mg}$ ) are added into CMAQ and the default thermodynamic module (i.e., ISORROPIA v1.7) in CMAQv4.7 is replaced by ISORROPIA II, to study the impact of those crustal species on the inorganic gas/particle partitioning through aerosol thermodynamic equilibrium. This implementation of crustal species treatment is expected to provide a more complete picture of the physical and chemical processes associated with mineral dust.

The emissions of crustal species are based on the onlinecalculated dust emissions. Since CMAQ v4.7 simulates the gas/particle partitioning in all three PM size modes (i.e., Aiken, accumulation, and coarse modes), the emissions of crustal species are specified for both fine- and coarse-mode 
dust. Ten percent of the emitted crustal species are assumed to be in accumulation mode and $90 \%$ are in coarse mode (Midwest Research Institute, 2005). In the model, crustal species are also treated spatially uniformed, which means all emissions of the crustal species are proportional to those of dust because of the lack of information on the chemical composition and mineralogy of dust particles. The emission ratio between crustal species and dust is assumed to be $1.022 \times 10^{-3}, 1.701 \times 10^{-3}$, and $7.08 \times 10^{-4}$ for $\mathrm{K}, \mathrm{Ca}$, and $\mathrm{Mg}$, respectively, based on Van Pelt and Zobeck (2007).

\section{Model configurations and evaluation protocols}

CMAQ-Dust is applied to the April 2001 dust episode during which frequent intercontinental transport and severe dust storms occurred (Jaffe et al., 2003; Wang et al., 2009). CMAQ v4.7 reflects a number of major updates to improve the underlying science from older versions (e.g., CMAQ v4.4 used by the previous ICAP study conducted by Wang et al., 2009). These enhancements include inclusion of coarsemode aerosol chemistry (Pilinis et al., 2000; Capaldo et al., 2000); addition of the new gas-chemistry mechanism, i.e., the Carbon Bond Mechanism version 2005 (CB05) and associated Euler backward iterative (EBI) solver; incorporation of online sea salt emission module; update on aerosol dry deposition algorithm; enhancement of SOA module by considering SOA products from isoprene, sesquiterpene, etc.; modification of the calculation of heterogeneous $\mathrm{N}_{2} \mathrm{O}_{5}$ reaction probability to be a function of temperature, relative humidity, and aerosol compositions.

The modeling domain is the same as the ICAP domain, which includes Eastern Asia, North America, Northern Pacific Ocean, and Western Atlantic Ocean with several active dust source regions (Western India, Northwest/Central China, and the Western US). The horizontal grid resolution is $108 \mathrm{~km}$, and vertical resolution includes 16 layers from the surface to approximately $100 \mathrm{hPa}$ (at $\sim 16 \mathrm{~km}$ ) with a finer spacing within the planetary boundary layer (PBL) and $\sim 40 \mathrm{~m}$ for the first model layer height. The meteorological field is generated by Weather Research \& Forecasting Model (WRF) version 3.2 with the analysis four-dimensional data assimilation (FDDA). The physical/chemical options used for the WRF/CMAQ-Dust simulation include Yonsei University (YSU) PBL scheme (Hong et al., 2006), thermal diffusion land surface parameterization scheme (Dubia, 1996), Grell 3-D ensemble cumulus cloud scheme (Grell and Devenyi, 2002), WRF Single Moment (WSM) 6-class graupel microphysics parameterization scheme (Hong and Lim, 2006), the Goddard shortwave radiation scheme (Chou and Suarez, 1994), the Rapid Radiative Transfer Model (RRTM) longwave radiation scheme (Mlawer et al., 1997), CB05 gasphase chemistry mechanism (Yarwood et al., 2005), and AERO5 aerosol mechanism (Roselle et al., 2008). The initial/boundary conditions (IBC) for WRF simulation are from the NCEP/NCAR Final Analysis (FNL) dataset. We have also conducted some sensitivity WRF simulations with other physical options or IBC (e.g., Community Climate System Model (CCSM) dataset). The above options and the FNL dataset with nudging give the best overall model performance and thus are used in the final simulations as described in Table 3. The WRF hourly outputs are converted to CMAQ compatible meteorological inputs with the MeteorologyChemistry Interface Processor (MCIP) version 3.5.

The emissions for anthropogenic sources are obtained from Wang et al. (2009). The emission data for the US are based on the National Emissions Inventory (NEI) 1999 version 1. The emission inventory for Mexico is prepared from the Big Bend Regional Aerosol and Visibility Observational Study (BRAVO) 1999 database. For Canada, the 1995 area and mobile (on-road and non-road) source inventory is used. The emission inventory in Asia is generated from the Transport and Chemical Evolution over the Pacific (TRACE-P) and the Aerosol Characterization ExperimentAsia (ACE-Asia) datasets (Streets et al., 2003). The biogenic emissions are prepared using the Biogenic Emissions Inventory System (BEIS) version 3.9 with Biogenic Emissions Land cover Database version 3 (BELD3) data (ICAP, 2005). Emissions from continuously emitting volcanoes are also included based on the Global Emissions Inventory Activity (GEIA). The sea salt and dust emissions are generated online using the method from Zhang et al. (2005) and the one developed by this study, respectively. The IBC for chemical species are taken from GEOS-Chem (Park et al., 2004).

To investigate the impacts of dust, a total of ten 1-month (April 2001) simulations are conducted, as listed in Table 3 (note that the Zender scheme is used for all simulations except for the simulation DUST_W). These simulations are designed to examine the differences between two dust schemes (i.e., DUST vs. DUST_W), and to understand the individual impacts of crustal species treatment in ISORROPIA II in the absence and presence of heterogeneous chemistry (i.e., the simulation CRUST_ONLY vs. the simulation DUST_EMIS_ONLY; DUST vs. DUST_ISO1.7), heterogeneous chemistry on the surface of dust (i.e., the simulation DUST vs. the simulation CRUST_ONLY), and their combined impacts (the simulation DUST vs. the simulation BASELINE_NO_DUST); the uncertainties in major parameters (e.g., the impact of the fraction of erodible lands for dust emissions by comparing DUST_HIGH_EF vs. DUST; the impact of uptake coefficients by comparing DUST_HIGH_UPTAKE vs. DUST); the impact of Asian anthropogenic emissions on the US air quality (DUST vs. DUST_NO_ASIA_EMIS); and the impact of improved aerosol treatments on the model performance (e.g., DUST vs. DEFAULT CMAQ v4.7).

The model evaluation for meteorological and chemical variables is conducted using the same protocols as introduced in Wang et al. (2009). The statistical measures used here include the mean bias (MB), correlation coefficient $(R)$, 
Table 3. Simulation design and purposes.

\begin{tabular}{|c|c|c|}
\hline Run Index & Model Configuration & Purpose \\
\hline DEFAULT CMAQ v4.7 & $\begin{array}{l}\text { WRF v3.2 and default CMAQ v4.7 } \\
\text { (uses ISORROPIA 1.7) but without any } \\
\text { dust treatments }\end{array}$ & $\begin{array}{l}\text { Performance comparison with MM5/CMAQ v4.4 of } \\
\text { Wang et al. (2009) }\end{array}$ \\
\hline BASELINE_NO_DUST & $\begin{array}{l}\text { Same as DEFAULT CMAQ v4.7 but } \\
\text { with ISORROPIA II }\end{array}$ & Serves as a baseline run for the run DUST \\
\hline DUST_EMIS_ONLY & $\begin{array}{l}\text { Same as BASELINE_NO_DUST but } \\
\text { with dust emissions only }\end{array}$ & Serves as a baseline run for the run CRUST_ONLY \\
\hline CRUST_ONLY & $\begin{array}{l}\text { Same as BASELINE_NO_DUST but } \\
\text { with dust emission and crustal species } \\
\text { treatment }\end{array}$ & $\begin{array}{l}\text { Differences between CRUST_ONLY and } \\
\text { DUST_EMIS_ONLY indicate the effect of crustal } \\
\text { species treatment only (see Figs. } 4 \text { and 5); serves as a } \\
\text { baseline for DUST_HIGH_UPTAKE }\end{array}$ \\
\hline DUST & $\begin{array}{l}\text { Same as BASELINE_NO_DUST but } \\
\text { with all dust treatments (emissions, } \\
\text { crustal species treatment, and hetero- } \\
\text { geneous chemistry using lower limit } \gamma \\
\text { values) }\end{array}$ & $\begin{array}{l}\text { Performance comparison with BASELINE_NO_DUST; } \\
\text { differences between DUST and CRUST_ONLY repre- } \\
\text { sent a lower bound of the effect of dust heterogeneous } \\
\text { chemistry (see Fig. 7); differences between DUST and } \\
\text { BASELINE_NO_DUST represent a lower bound of dust } \\
\text { effect with all dust treatments (see Figs. 8-10) }\end{array}$ \\
\hline DUST_W & $\begin{array}{l}\text { Same as DUST but with the Westphal } \\
\text { dust scheme }\end{array}$ & $\begin{array}{l}\text { Performance comparison with DUST (see Table } 4 \text { and } \\
\text { Fig. 3) }\end{array}$ \\
\hline DUST_HIGH_UPTAKE & $\begin{array}{l}\text { Same as DUST but using upper limit } \gamma \\
\text { values }\end{array}$ & $\begin{array}{l}\text { Differences between DUST_HIGH_UPTAKE and } \\
\text { CRUST_ONLY represent an upper bound of the effect } \\
\text { of dust heterogeneous chemistry (see Fig. 7) }\end{array}$ \\
\hline DUST_ISO1.7 & $\begin{array}{l}\text { Same as DUST but with ISORROPIA } \\
1.7\end{array}$ & $\begin{array}{l}\text { Differences between DUST and DUST_ISO1.7 indicate } \\
\text { the effect of crustal species treatment when dust hetero- } \\
\text { geneous chemistry is treated (see Fig. } 6 \text { ) }\end{array}$ \\
\hline DUST_HIGH_EF & Same as DUST but with $E_{\mathrm{F}}=1.0$ & $\begin{array}{l}\text { Differences between DUST_HIGH_EF and BASE- } \\
\text { LINE_NO_DUST represent an upper bound of dust ef- } \\
\text { fect with higher dust emissions and all dust treatments } \\
\text { (see Figs. 8-10) }\end{array}$ \\
\hline DUST_NO_ASIA_EMIS & $\begin{array}{l}\text { Same as DUST but without Asian } \\
\text { anthropogenic emissions }\end{array}$ & $\begin{array}{l}\text { Differences between DUST and } \\
\text { DUST_NO_ASIA_EMIS indicate the impact of } \\
\text { Asian anthropogenic emissions on the US air quality } \\
\text { (see Fig. 11) }\end{array}$ \\
\hline
\end{tabular}

the normalized mean bias (NMB), the normalized mean error (NME), and the root-mean-square error (RMSE) (Zhang et al., 2006). The WRF v3.2 simulation results are evaluated against the observational data from the Clean Air Status and Trends Network (CASTNET), the Speciation Trends Network (STN), and the National Acid Deposition Program (NADP) over the US and the National Climate Data Center (NCDC) of NOAA over China. Dust emission schemes are evaluated against measurements of dust concentrations from ten surface sites of Asia compiled by Cheng et al. (2008) and also measurements of AOD at four sites from the NASA's ground-based Aerosol Robotic Network (AERONET; http://aeronet.gsfc.nasa.gov/). Chemical predictions of CMAQ-Dust are evaluated against the avail- able ground- and satellite-based measurements. Surface observational data include those from the CASTNET, the Interagency Monitoring of Protected Visual Environments (IMPROVE), STN, the Aerometric Information Retrieval System (AIRS)-Air Quality System (AQS), the Southeastern Aerosol Research and Characterization study (SEARCH) over the US; those from the National Environmental Monitoring Centre of China (NEMCC) over China, and chemical data from the National Institute for Environmental Studies (NIES) over Japan. Satellite column data include tropospheric carbon monoxide ( $\mathrm{CO}$ ) columns from the Measurements of Pollution in the Troposphere (MOPITT) (Deeter et al., 2003), tropospheric nitrogen dioxide $\left(\mathrm{NO}_{2}\right)$ column from the Global Ozone Monitoring Experiment (GOME) 
Table 4. The comparison of monthly mean surface dust concentration $\left(\mathrm{mg} \mathrm{m}^{-3}\right)$ between observations and simulations for April 2001. The observational data were compiled by Cheng et al. (2008). The simulations DUST, DUST_W, and DUST_HIGH_EF are defined in Table 3.

\begin{tabular}{lcccccc}
\hline Site Location & Latitude & Longitude & Obs. & DUST & DUST_W & DUST_HIGH_EF \\
\hline Lanzhou - China & 36.05 & 103.88 & 0.305 & 0.163 & 0.154 & 0.313 \\
Shapotou - China & 37.50 & 105.00 & 0.370 & 0.220 & 0.215 & 0.429 \\
Changwu - China & 35.02 & 107.68 & 0.211 & 0.153 & 0.116 & 0.281 \\
Zhenbeitai - China & 38.29 & 109.70 & 0.209 & 0.203 & 0.138 & 0.389 \\
Inner Mongolia - China & 42.67 & 115.95 & 0.447 & 0.095 & 0.050 & 0.178 \\
Beijing - China & 39.93 & 116.35 & 0.206 & 0.114 & 0.078 & 0.188 \\
Gosan - South Korea & 33.29 & 126.16 & 0.052 & 0.034 & 0.030 & 0.049 \\
Seoul - South Korea & 37.53 & 127.07 & 0.093 & 0.045 & 0.042 & 0.057 \\
Nagoya - Japan & 35.15 & 136.96 & 0.038 & 0.021 & 0.021 & 0.027 \\
Tsukuba - Japan & 36.06 & 140.14 & 0.036 & 0.019 & 0.019 & 0.023 \\
\hline Average & & & 0.197 & 0.107 & 0.086 & 0.193 \\
\hline
\end{tabular}

(Burrows et al., 1999), tropospheric $\mathrm{O}_{3}$ residuals (TORs) from the Total Ozone Mapping Spectrometer (TOMS) and the Solar Backscattered Ultraviolet (SBUV) (Fishman et al., 2003), and AOD from the Moderate Resolution Imaging Spectroradiometer (MODIS) (Remer et al., 2005). More information about observations can be found in Wang et al. (2009).

The AOD calculations follow the method introduced by Roy (2007) using an empirical equation of Malm et al. (1994) and are further improved by considering the contributions from sea salts, dust, and other coarse-mode particles in this study. The scattering coefficient $\sigma_{\mathrm{sp}}$ is calculated as follows:

$$
\begin{aligned}
& \sigma_{\mathrm{sp}}=\sigma_{\mathrm{sp}}^{\mathrm{SO}_{4}}+\sigma_{\mathrm{sp}}^{\mathrm{NO}_{3}}+\sigma_{\mathrm{sp}}^{\mathrm{OC}}+\sigma_{\mathrm{sp}}^{\mathrm{BC}}+\sigma_{\mathrm{sp}}^{\mathrm{NH}_{4}}+\sigma_{\mathrm{sp}}^{\mathrm{Na}}+\sigma_{\mathrm{sp}}^{\mathrm{Cl}}+\sigma_{\mathrm{sp}}^{\mathrm{FS}}+\sigma_{\mathrm{sp}}^{\mathrm{CM}} \\
& =\left\{\left[\mathrm{SO}_{4}\right] \times \alpha_{\mathrm{sp}}^{\mathrm{SO}_{4}}+\left[\mathrm{NO}_{3}\right] \times \alpha_{\mathrm{sp}}^{\mathrm{NO}_{3}}+[\mathrm{OC}] \times \alpha_{\mathrm{sp}}^{\mathrm{OC}}+[\mathrm{BC}] \times \alpha_{\mathrm{sp}}^{\mathrm{BC}}\right. \\
& \left.+\left[\mathrm{NH}_{4}\right] \times \alpha_{\mathrm{sp}}^{\mathrm{NH}_{4}}+[\mathrm{Na}] \times \alpha_{\mathrm{sp}}^{\mathrm{Na}}+[\mathrm{Cl}] \times \alpha_{\mathrm{sp}}^{\mathrm{Cl}}\right\} \\
& \quad \times f(\mathrm{RH}) / 1.0 \times 10^{6}+\left\{[\mathrm{FS}] \times \alpha_{\mathrm{sp}}^{\mathrm{FS}}+[\mathrm{CM}] \times \alpha_{\mathrm{sp}}^{\mathrm{CM}}\right\} / 1.0 \times 10^{6}
\end{aligned}
$$

where $\sigma_{\mathrm{sp}}^{\mathrm{SO}_{4}}, \sigma_{\mathrm{sp}}^{\mathrm{NO}_{3}}, \sigma_{\mathrm{sp}}^{\mathrm{OC}}, \sigma_{\mathrm{sp}}^{\mathrm{BC}}, \sigma_{\mathrm{sp}}^{\mathrm{NH}_{4}}, \sigma_{\mathrm{sp}}^{\mathrm{Na}}, \sigma_{\mathrm{sp}}^{\mathrm{Cl}}, \sigma_{\mathrm{sp}}^{\mathrm{FS}}$, and $\sigma_{\mathrm{sp}}^{\mathrm{CM}}$ are the scattering coefficients for $\mathrm{SO}_{4}^{2-}, \mathrm{NO}_{3}^{-}$, OC, $\mathrm{BC}, \mathrm{NH}_{4}^{+}, \mathrm{Na}^{+}$, and $\mathrm{Cl}^{-}$in the $\mathrm{PM}_{2.5}$ size section, fine-mode soil including dust and other inorganic aerosols, and coarse masses including coarse-mode dust, sea-salt, and other aerosols, respectively, and the brackets in the above equation indicate the mass concentration in $\mu \mathrm{g} \mathrm{m}^{-3}$. The values for specific scattering coefficients $\left(\alpha_{\mathrm{sp}}^{i}\right)$ for species $i$ are $\alpha_{\mathrm{sp}}^{\mathrm{SO}_{4}}=\alpha_{\mathrm{sp}}^{\mathrm{NO}_{3}}=\alpha_{\mathrm{sp}}^{\mathrm{OC}}=\alpha_{\mathrm{sp}}^{\mathrm{NH}_{4}}=\alpha_{\mathrm{sp}}^{\mathrm{Na}}=$ $\alpha_{\mathrm{sp}}^{\mathrm{Cl}}=5.0 \mathrm{~m}^{2} \mathrm{~g}^{-1}, \alpha_{\mathrm{sp}}^{\mathrm{BC}}=3.0 \mathrm{~m}^{2} \mathrm{~g}^{-1}, \alpha_{\mathrm{sp}}^{\mathrm{FS}}=1.0 \mathrm{~m}^{2} \mathrm{~g}^{-1}$, and $\alpha_{\mathrm{sp}}^{\mathrm{CM}}=0.6 \mathrm{~m}^{2} \mathrm{~g}^{-1}$ (Malm et al., 1994). $f(\mathrm{RH})$ accounts for the effect of relative humidity on scattering due to deliquescence and is assumed to be 2.3 in this study following Chameides et al. (2002).

\section{Model evaluation}

\subsection{Evaluation of meteorological variables}

Table 5 summarizes the statistical performance of 2-m temperature (T2), 2-m water vapor mixing ratio (Q2) or relative humidity (RH2), precipitation (Precip), 10-m wind speed (WS10) and wind direction (WD10), and $U$ and $V$ components of WS10 (i.e., U10 and V10) over different networks in China and the US in April 2001. Figures S-1 and S-2 in the Supplement show the spatial plots of NMBs between observations and MM5/WRF simulations for T2, Q2 or RH2, Precip, and WS10 over China and the US, respectively. WRF generally underpredicts $\mathrm{T} 2$ over China with domain-wide NMB of $-20.6 \%$, especially over the Northern and Western China where NMBs of $-40 \%$ to $-100 \%$ occur. Some overpredictions occur in the Southwestern China. The poor T2 predictions over the Western China are likely due to the poor representation of steep terrains at a coarse grid resolution (Wang et al., 2009). The predictions of T2 over the US have low domain-wide biases with NMBs of $4.9 \%$ (CASTNET) and $-4.2 \%$ (STN) with small overpredictions over the Northeastern US and moderate to large underpredictions over the Western US. The discrepancies arise from several factors, including the slow responses of deep soil temperatures to synoptic-scale changes in air temperatures, the limitations of the PBL and land-surface schemes currently used in meteorological models in accurately simulating the airland heat fluxes (Gilliam et al., 2006), the limitation of Dudhia (1989) radiation scheme in simulating the longwave radiation, as well as the inability to resolve subgrid meteorological phenomena (Wang et al., 2009). The correlation coefficients for T2 are very high over all networks with R-values of 0.88 for CASTNET, 0.87 for STN, and 0.87 for NCDC, respectively. For Q2 or RH2, the model also performs well in terms of both spatial distribution and statistical performance. The domain-wide average NMBs are $8.1 \%$ for Q2 against 
Table 5. Performance statistics for meteorological predictions over the US and China from MM5 and WRF simulations in April 2001.

\begin{tabular}{|c|c|c|c|c|c|c|c|c|c|c|c|c|}
\hline & \multirow[t]{2}{*}{ Variables } & \multicolumn{6}{|c|}{ CASTNET (US) $^{\mathrm{a}}$} & \multirow{2}{*}{$\begin{array}{r}\mathrm{STN}(\mathrm{US}) \\
\mathrm{T} 2 \\
\left({ }^{\circ} \mathrm{C}\right)\end{array}$} & \multirow{2}{*}{$\begin{array}{r}\text { NADP (US) } \\
\text { Precip. } \\
(\mathrm{mm})\end{array}$} & \multicolumn{3}{|c|}{ NCDC (China) ${ }^{b}$} \\
\hline & & $\begin{array}{r}\mathrm{T} 2 \\
\left({ }^{\circ} \mathrm{C}\right)\end{array}$ & $\begin{array}{r}\mathrm{RH} 2 \\
(\%)\end{array}$ & $\begin{array}{r}\text { WS10 } \\
\left(\mathrm{m} \mathrm{s}^{-1}\right)\end{array}$ & $\begin{array}{r}\text { WD10 } \\
\text { (degree) }\end{array}$ & $\begin{array}{r}\text { U10 } \\
\left(\mathrm{m} \mathrm{s}^{-1}\right)\end{array}$ & $\begin{array}{r}\mathrm{V} 10 \\
\left(\mathrm{~m} \mathrm{~s}^{-1}\right)\end{array}$ & & & $\begin{array}{r}\mathrm{T} 2 \\
\left({ }^{\circ} \mathrm{C}\right)\end{array}$ & $\begin{array}{r}\mathrm{Q} 2 \\
\left(\mathrm{~kg} \mathrm{~kg}^{-1}\right)\end{array}$ & $\begin{array}{r}\text { Precip. } \\
(\mathrm{mm})\end{array}$ \\
\hline & Data Number & 50030 & 53975 & 53909 & 53909 & 53909 & 53909 & 511 & 665 & 89437 & 35008 & 2022 \\
\hline & Mean Obs. & 12.2 & 61.7 & 2.7 & 190.0 & 0.6 & 0.3 & 15.0 & 17.8 & 13.1 & 0.00545 & 2.3 \\
\hline \multirow{6}{*}{$\begin{array}{l}\text { WRF (CCSM) } \\
\text { with PBL } \\
\text { nudging }\end{array}$} & Mean Pred. & 13.6 & 67.4 & 5.4 & 207.7 & 1.7 & 1.5 & 15.4 & 6.4 & 9.7 & 0.00528 & 0.65 \\
\hline & Correlation & 0.61 & 0.40 & 0.21 & 0.13 & 0.06 & 0.17 & 0.56 & 0.12 & 0.72 & 0.73 & 0.03 \\
\hline & MB & 1.4 & 5.8 & 2.7 & 17.6 & 1.1 & 1.2 & 0.4 & -11.4 & -3.4 & -0.00017 & -1.65 \\
\hline & RMSE & 7.0 & 23.7 & 4.0 & 122.7 & 8.3 & 4.5 & 6.4 & 26.2 & 7.5 & 0.00272 & 6.12 \\
\hline & NMB (\%) & 11.8 & 9.4 & 97.7 & 9.3 & 184.7 & 383.1 & 2.8 & -64.1 & -25.8 & -3.1 & -71.6 \\
\hline & NME (\%) & 45.7 & 31.1 & 118.1 & 49.8 & 590.9 & 1121.0 & 34.1 & 95.5 & 44.6 & 37.8 & 108.9 \\
\hline \multirow{6}{*}{$\begin{array}{l}\text { WRF (FNL) } \\
\text { without PBL } \\
\text { nudging }\end{array}$} & Mean Pred. & 12.8 & 70.3 & 4.6 & 204.9 & 1.3 & 0.6 & 14.3 & 8.3 & 10.7 & 0.00596 & 1.7 \\
\hline & Correlation & 0.89 & 0.70 & 0.55 & 0.48 & 0.20 & 0.70 & 0.87 & 0.57 & 0.88 & 0.92 & 0.31 \\
\hline & $\mathrm{MB}$ & 0.6 & 8.6 & 1.9 & 14.9 & 0.7 & 0.3 & -0.7 & -9.5 & -2.5 & 0.00051 & -0.63 \\
\hline & RMSE & 3.6 & 19.3 & 2.8 & 100.9 & 7.6 & 2.6 & 3.6 & 19.8 & 5.1 & 0.00168 & 5.63 \\
\hline & NMB (\%) & 5.2 & 14.0 & 69.2 & 7.8 & 116.8 & 78.7 & -4.4 & -53.4 & -18.8 & 9.3 & -27.5 \\
\hline & $\operatorname{NME}(\%)$ & 22.4 & 24.6 & 82.5 & 32.7 & 369.9 & 642.1 & 17.7 & 69.8 & 29.3 & 23.5 & 102.5 \\
\hline \multirow{6}{*}{$\begin{array}{l}\text { WRF (FNL) } \\
\text { with UV PBL } \\
\text { nudging }\end{array}$} & Mean Pred. & 12.8 & 70.4 & 4.0 & 202.1 & 1.0 & 0.8 & 14.3 & 8.2 & 10.4 & 0.00589 & 1.6 \\
\hline & Correlation & 0.88 & 0.68 & 0.54 & 0.50 & 0.21 & 0.72 & 0.87 & 0.56 & 0.87 & 0.91 & 0.35 \\
\hline & MB & 0.6 & 8.8 & 1.2 & 12.0 & 0.4 & 0.5 & -0.6 & -9.6 & -2.7 & 0.00044 & -0.72 \\
\hline & RMSE & 3.7 & 19.7 & 2.3 & 96.1 & 7.5 & 2.3 & 3.6 & 19.9 & 5.4 & 0.00169 & 5.42 \\
\hline & NMB (\%) & 4.9 & 14.2 & 45.6 & 6.3 & 76.6 & 158.0 & -4.2 & -54.1 & -20.6 & 8.1 & -31.5 \\
\hline & NME (\%) & 23.2 & 25.0 & 67.4 & 30.8 & 310.2 & 549.6 & 17.9 & 70.0 & 31.1 & 23.6 & 97.6 \\
\hline \multirow[t]{6}{*}{ MM5 } & Mean Pred. & 9.9 & 71.5 & 3.1 & 182.0 & 0.1 & 0.8 & 11.5 & 13.3 & 9.34 & 0.0049 & 1.98 \\
\hline & Correlation & 0.85 & 0.60 & 0.57 & 0.14 & 0.09 & 0.30 & 0.88 & 0.57 & 0.88 & 0.94 & 0.44 \\
\hline & MB & -2.3 & 9.8 & 0.4 & -8.1 & -0.5 & 0.5 & -3.5 & -5.9 & -3.8 & -0.00053 & -0.32 \\
\hline & RMSE & 5.0 & 28.2 & 1.8 & 124.7 & 7.7 & 2.9 & 5.0 & 18.3 & 5.9 & 0.00154 & 5.31 \\
\hline & NMB (\%) & -19.2 & 15.9 & 15.4 & -4.2 & -77.7 & 163.2 & -23.1 & -30.8 & -28.8 & -9.8 & -14.0 \\
\hline & $\operatorname{NME}(\%)$ & 30.8 & 33.2 & 52.1 & 51.1 & 406.6 & 714.9 & 25.2 & 60.3 & 34.3 & 21.8 & 102.4 \\
\hline
\end{tabular}

${ }^{a}$ Data from CASTNET include T2, RH2, WS10, WD10, U10 and V10.

${ }^{b}$ Data from NCDC include T2, Q2, and Precip.

NCDC and $14.2 \%$ for RH2 against CASTNET and R-values are 0.91 and 0.68 , respectively. Their NMBs over the majority of NCDC and CASTNET sites are within $\pm 20 \%$. Relatively high NMBs are found in the Northern and Western China and the Western US, indicating a poor performance of WRF over complex terrains. WRF precipitation predictions rank poorly compared to T2 and RH2 (or Q2), likely because WRF cannot capture small-scale dynamical processes, topography, and rapid diurnal evolution of PBL with relatively large grid resolution (Kursinski et al., 2008), with lower domain-wide mean underpredictions in China compared to in the US (NMBs of $-31.5 \%$ vs. $-54.1 \%$ ). The spatial distribution of NMBs in China, however, displays a worse pattern, with large negative biases $(<-70 \%)$ occurring mostly over the Northwestern, Northeastern and Eastern China and large positive biases (>70\%) occurring mostly over the Southwestern China. The overall small domain-wide mean NMB for precipitation over China is therefore the result of the cancellation of large positive and negative biases. WRF generally overpredicts WS10 (e.g., an overall NMB of $45.6 \%$ against CASTNET), indicating that WRF meteorology favors dust emissions. However, the overprediction is much less over the dust source regions in both China and the US. The performance statistics for other WRF simulations (e.g., CCSM data and other nudging options) are also included in Table 5. The WRF simulation using FNL data and UV PBL nudging gives overall the best performance and thus is used for all the CMAQ-Dust simulations. Comparing with the simulation results of MM5, WRF predicts higher WS10 (i.e., domain-wide average $4.0 \mathrm{~m} \mathrm{~s}^{-1}$ versus $3.1 \mathrm{~m} \mathrm{~s}^{-1}$ ), indicating that WRF meteorology in CMAQ v4.7 favors the dust emissions. Much higher correlation for WD10 (i.e., R-values of 0.5 vs. 0.14) and smaller error (i.e., NME of $30.8 \%$ vs. $51.1 \%$ against CASTNET data) indicate a much better agreement of the wind field generated by WRF with observations. Generally, WRF predicts much better T2 and slightly better RH2 than MM5 especially over the US. However, WRF predictions for precipitation are worse.

\subsection{Evaluation of chemical variables}

\subsubsection{Dust emission fluxes and dust concentrations}

Figure 1 shows the predicted monthly mean dust emission rate generated by the Zender and Westphal schemes with $E_{\mathrm{F}}$ of 0.5 and total dust concentrations in $\mathrm{PM}_{10}$ at surface and $\sim 5 \mathrm{~km}$ altitude from the Zender scheme only with $E_{\mathrm{F}}$ of 


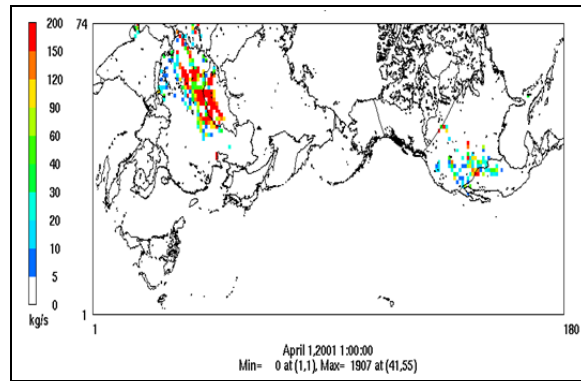

(a) Monthly mean dust emissions from the

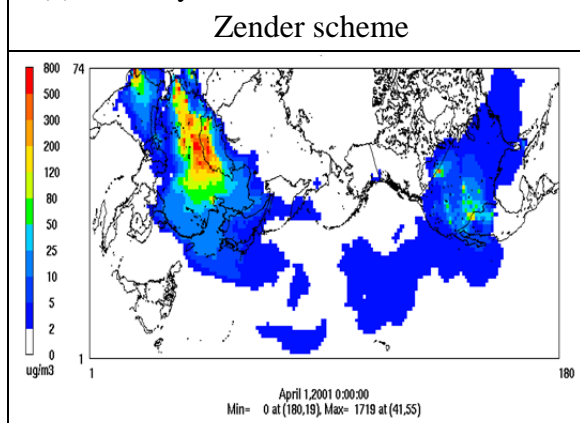

(c) Monthly mean dust concentration at surface with $\mathrm{E}_{\mathrm{F}}$ of 0.5

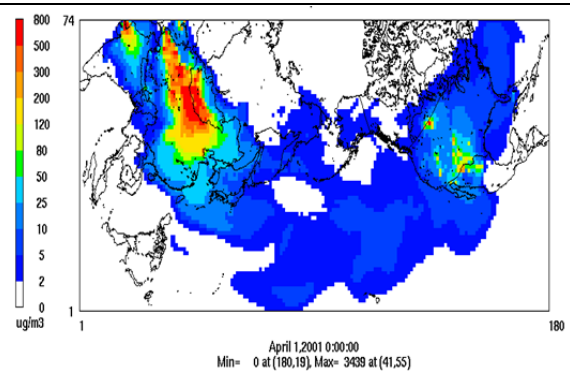

(e) Monthly mean dust concentration at surface with $\mathrm{E}_{\mathrm{F}}$ of 1.0

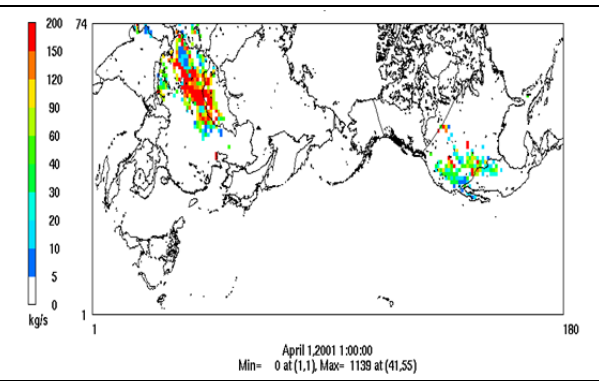

(b) Monthly mean dust emissions from the Westphal scheme

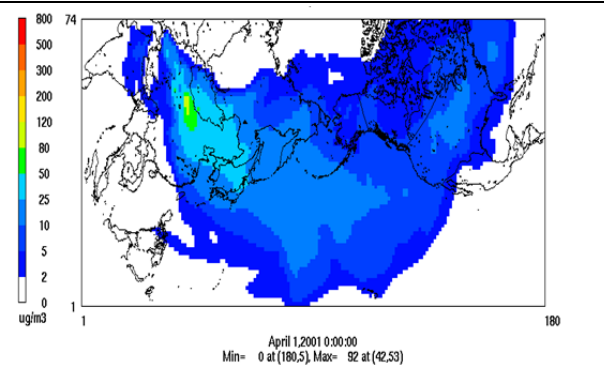

(d) Monthly mean dust concentration at $\sim 5 \mathrm{~km}$ with $\mathrm{E}_{\mathrm{F}}$ of 0.5

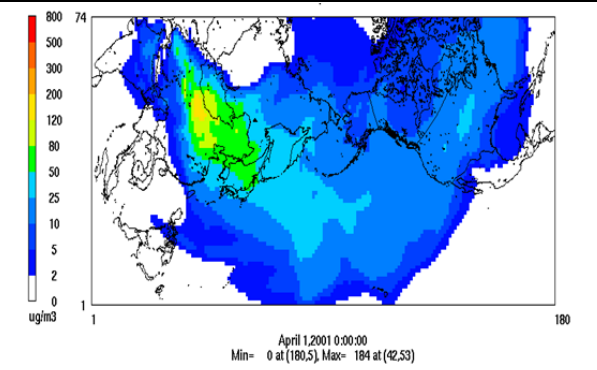

(f) Monthly mean dust concentration at $\sim 5 \mathrm{~km}$ with $\mathrm{E}_{\mathrm{F}}$ of 1.0

Fig. 1. The predicted monthly mean dust emission rates generated by (a) Zender and (b) Westphal schemes with $E_{\mathrm{F}}$ of 0.5 , and (c-f) for total dust concentrations at surface and $\sim 5 \mathrm{~km}$ altitude from the Zender scheme with $E_{\mathrm{F}}$ of 0.5 and 1.0 in CMAQ-Dust.

0.5 and 1.0. The altitude aloft chosen is typically associated with long-range transport of dust and pollutants. In general, from both schemes, dust emissions occur over regions where high wind speeds, low vegetation, and no snow cover occur. The areas with the strongest sources are located in the Taklamakan Desert and Gobi Desert over China and Mongolia. Areas with less pronounced dust sources include the Western India, the Southwestern and Great Plains regions over the US, and Sonoran Desert of Mexico. The spatial pattern of dust emissions is consistent with previous studies (Ginoux et al., 2001; Prospero et al., 2002, Zender et al., 2003; Tang et al., 2004). CMAQ-Dust also captures the dust outbreak event during 4-14 April (figures not shown). The monthly total dust emissions generated by CMAQ-Dust using the Zender and Westphal schemes with $E_{\mathrm{F}}=0.5$ are 111.4 and $110.9 \mathrm{Tg}_{\text {month }}{ }^{-1}$, respectively. Increasing $E_{\mathrm{F}}$ from 0.5 to
1.0 in the Zender scheme gives $223.0 \mathrm{Tg}$ month $^{-1}$. These values are overall consistent with estimates reported in the literature. For example, Zender et al. (2003) estimated an annual dust emission of $415 \mathrm{Tg}$ over Asia. Laurent et al. (2006) estimated dust emissions of $300 \mathrm{Tg}$ over China in April 2001. Uno et al. (2006) reported 27 to $336 \mathrm{Tg}$ dust emissions during a 10-day period in a dust season over China, with a mean of $120 \mathrm{Tg}$ from eight different dust models. The amounts of dust emissions from simulations DUST and DUST_HIGH_EF represent lower and upper limits of estimates, respectively, for the April 2001 dust event.

As shown in Fig. 1c-f, the maximum total surface concentrations of dust from DUST $\left(\geq 200 \mu \mathrm{g} \mathrm{m}^{-3}\right)$ and DUST_HIGH_EF $\left(\geq 500 \mu \mathrm{g} \mathrm{m}^{-3}\right)$ are apparent over source regions, where large particles have not deposited yet. The concentrations of dust in fine and coarse modes (referred 
Table 6. Performance statistics for chemical predictions over the US in April 2001.

\begin{tabular}{|c|c|c|c|c|c|c|c|c|c|c|c|c|}
\hline & \multirow[t]{2}{*}{ Variables } & AIRS & CASTNET & SEARCH & AIRS & CASTNET & SEARCH & IMPROVE & STN & SEARCH & & IPROVE $^{c}$ \\
\hline & & \multicolumn{3}{|c|}{$\operatorname{Max} 1 \mathrm{~h} \mathrm{O} 3(\mathrm{ppb})^{\mathrm{a}}$} & \multicolumn{3}{|c|}{$\operatorname{Max} 8 \mathrm{~h} \mathrm{O}_{3}(\mathrm{ppb})^{\mathrm{a}}$} & \multicolumn{3}{|c|}{$\mathrm{PM}_{2.5}\left(\mu \mathrm{g} \mathrm{m}^{-3}\right)^{\mathrm{b}}$} & DCV & $\operatorname{EXT}\left(\mathrm{Mm}^{-1}\right)$ \\
\hline & Data Number & 29993 & 2267 & 197 & 29276 & 2232 & 197 & 2125 & 365 & 87 & 1049 & 1049 \\
\hline & Mean Obs. & 52.7 & 54.3 & 56.4 & 47.8 & 50.4 & 51.4 & 5.7 & 11.1 & 14.3 & 12.6 & 31.4 \\
\hline \multirow{4}{*}{$\begin{array}{l}\text { MM5/CMAQ } \\
\text { v4.4 }\end{array}$} & Mean Pred. & 48.7 & 44.2 & 47.5 & 45.4 & 43.4 & 47.3 & 9.39 & 16.8 & 17.5 & - & - \\
\hline & Correlation & 0.54 & 0.51 & 0.71 & 0.53 & 0.62 & 0.75 & 0.29 & 0.41 & 0.67 & - & - \\
\hline & NMB (\%) & -7.3 & -18.5 & -15.7 & -4.7 & -13.8 & -7.7 & 55.7 & 51.5 & 15.4 & - & - \\
\hline & NME (\%) & 18.5 & 22.3 & 18.6 & 18.8 & 19.5 & 14.8 & 82.3 & 70.6 & 33.4 & - & - \\
\hline \multirow{4}{*}{$\begin{array}{l}\text { DEFAULT } \\
\text { CMAQ v4.7 }\end{array}$} & Mean Pred. & 54.1 & 48.9 & 49.9 & 51.1 & 48.1 & 49.6 & 7.0 & 11.9 & 11.2 & 12.8 & 47.6 \\
\hline & Correlation & 0.50 & 0.49 & 0.63 & 0.47 & 0.58 & 0.71 & 0.43 & 0.48 & 0.34 & 0.66 & 0.58 \\
\hline & NMB (\%) & 2.8 & -9.8 & -11.5 & 6.8 & -4.7 & -3.6 & 21.8 & 6.8 & -21.5 & 1.7 & 51.6 \\
\hline & $\operatorname{NME}(\%)$ & 16.6 & 17.0 & 17.6 & 17.9 & 15.5 & 14.8 & 55.1 & 42.2 & 52.2 & 27.2 & 71.9 \\
\hline \multirow[t]{4}{*}{ DUST } & Mean Pred. & 53.7 & 48.6 & 49.1 & 50.7 & 47.7 & 48.3 & 9.5 & 14.1 & 12.8 & 14.9 & 56.5 \\
\hline & Correlation & 0.49 & 0.48 & 0.63 & 0.47 & 0.57 & 0.71 & 0.32 & 0.40 & 0.37 & 0.66 & 0.55 \\
\hline & NMB (\%) & 2.0 & -10.5 & -12.9 & 5.9 & -5.4 & -4.2 & 66.3 & 26.5 & -10.1 & 17.9 & 79.7 \\
\hline & NME (\%) & 16.7 & 17.4 & 18.1 & 17.9 & 15.8 & 15.1 & 86.4 & 53.1 & 52.9 & 30.4 & 91.8 \\
\hline \multirow[t]{4}{*}{ DUST_W } & Mean Pred. & 53.7 & 48.5 & 49.2 & 50.6 & 47.6 & 48.3 & 11.4 & 15.1 & 12.8 & 15.7 & 61.0 \\
\hline & Correlation & 0.49 & 0.48 & 0.63 & 0.47 & 0.57 & 0.71 & 0.18 & 0.21 & 0.36 & 0.57 & 0.47 \\
\hline & NMB (\%) & 1.9 & -10.6 & -12.8 & 5.9 & -5.5 & -4.2 & 99.6 & 35.6 & -9.9 & 24.8 & 94.2 \\
\hline & NME (\%) & 16.6 & 17.4 & 18.0 & 17.9 & 15.8 & 15.0 & 118.1 & 61.2 & 53.3 & 35.9 & 105.7 \\
\hline DUST_ & Mean Pred. & 53.3 & 48.1 & 48.8 & 50.2 & 47.2 & 47.9 & 12.2 & 16.4 & 14.5 & 16.0 & 64.2 \\
\hline \multirow[t]{3}{*}{ HIGH_EF } & Correlation & 0.48 & 0.47 & 0.62 & 0.46 & 0.56 & 0.70 & 0.20 & 0.28 & 0.37 & 0.61 & 0.47 \\
\hline & NMB (\%) & 1.1 & -11.3 & -13.4 & 5.0 & -6.3 & -4.9 & 112.5 & 47.3 & 1.9 & 27.0 & 104.5 \\
\hline & NME (\%) & 16.8 & 17.9 & 18.5 & 18.0 & 16.2 & 15.4 & 128.7 & 70.7 & 57.0 & 36.2 & 113.9 \\
\hline
\end{tabular}

a Max $1 \mathrm{~h}$ and $8 \mathrm{~h} \mathrm{O}_{3}$ data are from AIRS, CASTNET, and SEARCH.

${ }^{\mathrm{b}} \mathrm{PM}_{2.5}$ data are from IMPROVE, STN, and SEARCH.

c The DCV and EXT data from the CMAQv4.4 simulation of Wang et al. (2009) are not available.

to as dust $_{\text {fine }}$ and dust coarse $_{\text {, respectively) }}$ are $\geq 50$ and $\geq 120 \mu \mathrm{g} \mathrm{m}^{-3}$ from DUST and $\geq 120$ and $\geq 200 \mu \mathrm{g} \mathrm{m}^{-3}$ from DUST_HIGH_EF, respectively over deserts in China (see Fig. S-3). Due to the much faster deposition rates of dust $_{\text {coarse }}$, the spatial distributions and abundance of dust $f_{\text {fine }}$

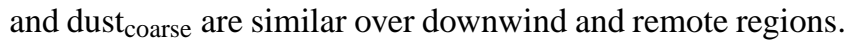
The total surface concentration of dust particles can reach up to 25 and $50 \mu \mathrm{g} \mathrm{m}^{-3}$ from DUST and DUST_HIGH_EF over the downwind areas such as the Eastern China, Japan, Northeast India, and the Midwest US. Long-range transport can build up the total surface concentrations of dust up to 5 to $10 \mu \mathrm{g} \mathrm{m}^{-3}$ over the remote regions such as the Eastern Pacific and the Eastern US. The total concentrations of dust over the downwind and remote areas at $\sim 5 \mathrm{~km}$ altitude are higher than the surface, indicating that the long-range transport of dust particles is more efficient at higher altitudes.

\subsubsection{Evaluation of chemical variables}

Table 4 shows the monthly mean surface dust concentrations from measurements compiled by Cheng et al. (2008) and simulations DUST, DUST_W, and DUST_HIGH_EF at ten sites in East Asia in April 2001. Among those sites, five are close to dust source regions (i.e., Lanzhou, Shapotou, Changwu, Zhenbeitai, and Inner Mongolia); one is in the near downwind regions (i.e., Beijing); the rest of the four sites are in the far downwind regions. Both simulations DUST and DUST_W underpredict dust concentra- tions by $45.7 \%$ and $56.3 \%$, respectively, indicating that the simulation DUST with the Zender scheme performs better than the Westphal scheme over almost all sites. The average dust concentration at the 10 sites is $0.107 \mathrm{mg} \mathrm{m}^{-3}$ from DUST vs. $0.086 \mathrm{mg} \mathrm{m}^{-3}$ from DUST_W. For comparison, the average observed value is $0.197 \mathrm{mg} \mathrm{m}^{-3}$. The simulation DUST_HIGH_EF with a higher EF value in the Zender scheme gives much better agreement with observations than both DUST and DUST_W, with an average dust concentration of $0.193 \mathrm{mg} \mathrm{m}^{-3}$, despite overpredictions near source regions and underpredictions over downwind regions.

Tables 6 and 7 summarize performance statistics of several major chemical/visibility species over the US, Beijing (China), and Japan among five simulations (i.e., simulations MM5/CMAQ v4.4 without dust, DEFAULT CMAQ v4.7, DUST, DUST_W, and DUST_HIGH_EF). The results of MM5/CMAQ v4.4 are included to reflect how much changes in CMAQ-DUST (based on CMAQ 4.7) are due to updates in CMAQ v4.7 or due to new dust treatments added in CMAQ v4.7. Over the US, the model performance for $\mathrm{O}_{3}$ from the simulation DUST is quite good with NMBs of $-12.9 \%$ to $2.0 \%$ and NMEs of $16.7 \%$ to $18.1 \%$ for max $1 \mathrm{~h} \mathrm{O}_{3}$ and with NMBs of $-5.4 \%$ to $5.9 \%$ and NMEs of $15.1 \%$ to $17.9 \%$ for $\max 8-\mathrm{h} \mathrm{O}_{3}$. All simulations with dust treatment tend to predict more $\mathrm{O}_{3}$ than with CMAQ v4.4 mainly due to the use of CB05 mechanism and a little bit less $\mathrm{O}_{3}$ than with simulation DEFAULT CMAQ v4.7 due 
Table 7. Performance statistics for chemical predictions over Asia in April 2001.

\begin{tabular}{|c|c|c|c|c|c|c|c|c|c|c|}
\hline & \multirow[t]{2}{*}{ Variables } & \multicolumn{4}{|c|}{ Beijing $^{a}$} & \multicolumn{5}{|c|}{ Japan $^{\text {b }}$} \\
\hline & & $\begin{array}{r}\operatorname{Max} 1 \mathrm{~h} \mathrm{O}_{3} \\
\quad\left(\mu \mathrm{g} \mathrm{m}^{-3}\right)\end{array}$ & $\begin{array}{r}\mathrm{SO}_{2} \\
\left(\mu \mathrm{g} \mathrm{m}^{-3}\right)\end{array}$ & $\begin{array}{r}\mathrm{NO}_{2} \\
\left(\mu \mathrm{g} \mathrm{m}^{-3}\right)\end{array}$ & $\begin{array}{r}\mathrm{PM}_{10} \\
\left(\mu \mathrm{g} \mathrm{m}^{-3}\right)\end{array}$ & $\begin{array}{r}\mathrm{CO} \\
(\mathrm{ppb})\end{array}$ & $\begin{array}{r}\mathrm{SO}_{2} \\
(\mathrm{ppb})\end{array}$ & $\begin{array}{r}\text { NO } \\
(\mathrm{ppb})\end{array}$ & $\begin{array}{l}\mathrm{NO}_{2} \\
(\mathrm{ppb})\end{array}$ & $\begin{array}{r}\text { SPM } \\
\left(\mu \mathrm{g} \mathrm{m}^{-3}\right)\end{array}$ \\
\hline & Data Number & 30 & 30 & 30 & 30 & 131 & 1490 & 1448 & 1465 & 1537 \\
\hline & Mean Obs. & 95.8 & 34.0 & 65.9 & 209.6 & 443.5 & 6.0 & 6.6 & 16.9 & 33.9 \\
\hline MM5/CMAQ & Mean Pred. & 86.8 & 37.3 & 15.3 & 34.0 & 192.0 & 4.5 & 0.6 & 6.6 & 17.0 \\
\hline \multirow[t]{3}{*}{$\mathrm{v} 4.4$} & Correlation & -0.03 & 0.28 & 0.38 & 0.14 & 0.27 & 0.35 & 0.21 & 0.44 & 0.16 \\
\hline & NMB (\%) & -9.36 & 9.80 & -76.8 & -83.6 & -56.7 & -25.5 & -91.1 & -60.7 & -49.7 \\
\hline & NME (\%) & 25.5 & 49.4 & 76.8 & 83.6 & 56.8 & 40.5 & 91.1 & 62.8 & 49.9 \\
\hline DEFAULT & Mean Pred. & 112.4 & 39.5 & 18.6 & 39.9 & 183.0 & 3.9 & 0.6 & 6.0 & 16.6 \\
\hline \multirow[t]{3}{*}{ CMAQ v4.7 } & Correlation & 0.01 & 0.17 & 0.25 & 0.13 & 0.30 & 0.39 & 0.19 & 0.48 & 0.15 \\
\hline & NMB (\%) & 17.3 & 16.2 & -71.8 & -80.9 & -58.7 & -35.2 & -91.1 & -64.2 & -50.9 \\
\hline & NME (\%) & 30.6 & 56.0 & 71.8 & 80.9 & 58.7 & 43.8 & 91.2 & 65.4 & 51.1 \\
\hline \multirow[t]{4}{*}{ DUST } & Mean Pred. & 108.9 & 38.8 & 18.5 & 113.6 & 183.0 & 3.9 & 0.6 & 6.0 & 22.1 \\
\hline & Correlation & 0.01 & 0.17 & 0.25 & 0.11 & 0.30 & 0.39 & 0.19 & 0.48 & 0.19 \\
\hline & NMB $(\%)$ & 13.7 & 14.2 & -71.9 & -45.8 & -58.7 & -35.5 & -91.1 & -64.3 & -34.7 \\
\hline & NME $(\%)$ & 27.7 & 55.1 & 71.9 & 79.9 & 58.7 & 44.0 & 91.1 & 65.4 & 35.8 \\
\hline \multirow[t]{4}{*}{ DUST_W } & Mean Pred. & 109.9 & 39.0 & 18.5 & 78.3 & 183.0 & 3.9 & 0.6 & 6.0 & 21.6 \\
\hline & Correlation & 0.03 & 0.17 & 0.25 & 0.15 & 0.30 & 0.39 & 0.19 & 0.48 & 0.20 \\
\hline & NMB (\%) & 14.7 & 14.7 & -72.0 & -62.6 & -58.7 & -35.5 & -91.1 & -64.3 & -36.2 \\
\hline & $\operatorname{NME}(\%)$ & 28.7 & 55.4 & 72.0 & 69.1 & 58.7 & 44.0 & 91.1 & 65.4 & 37.1 \\
\hline \multirow[t]{4}{*}{ DUST_HIGH_EF } & Mean Pred. & 106.7 & 38.3 & 18.5 & 188.1 & 183.0 & 3.8 & 0.6 & 6.0 & 27.7 \\
\hline & Correlation & 0.06 & 0.18 & 0.25 & 0.10 & 0.30 & 0.39 & 0.19 & 0.48 & 0.19 \\
\hline & $\operatorname{NMB}(\%)$ & 11.3 & 12.8 & -71.9 & -10.3 & -58.7 & -35.8 & -91.0 & -64.2 & -18.2 \\
\hline & NME $(\%)$ & 27.3 & 54.4 & 71.9 & 97.3 & 58.7 & 44.2 & 91.1 & 65.4 & 24.4 \\
\hline
\end{tabular}

a Data over Beijing include max $1 \mathrm{~h} \mathrm{O}_{3}, \mathrm{SO}_{2}, \mathrm{NO}_{2}$, and $\mathrm{PM}_{10}$.

b Data over Japan include CO, $\mathrm{SO}_{2}, \mathrm{NO}, \mathrm{NO}_{2}$, and SPM.

to the heterogeneous uptake of $\mathrm{O}_{3}$ on dust particles. Compared with the CMAQ v4.4, the simulation DUST predicts $\mathrm{PM}_{2.5}$ better at the SEARCH and STN sites (with NMBs of $-10.1 \%$ vs. $15.4 \%$ for SEARCH and $26.5 \%$ vs. $51.5 \%$ for STN), however, gives higher overpredictions at the IMPROVE sites (NMB increases from $55.7 \%$ to $66.3 \%$ ). The better performance over MM5/CMAQ v4.4 should be due to a better representation of aerosol chemistry in CMAQ-Dust. Compared with DUST_W, the simulation DUST predicts $\mathrm{PM}_{2.5}$ better at the IMPROVE and STN sites (with NMBs of $86.4 \%$ vs. $99.6 \%$ for SEARCH and $26.5 \%$ vs. $35.6 \%$ for STN) and gives similar performance at the SEARCH sites (i.e., NMB of $-10.1 \%$ vs. $-9.9 \%$ ) indicating a better overall performance for the Zender scheme than the Westphal scheme. The values of deciview (DCV) and extinction coefficient (EXT) are also overpredicted at the IMPROVE sites with high NMB values for all four simulations with dust treatments indicating some overestimation of dust emissions at the IMPROVE sites in the Western US. The overprediction of $\mathrm{PM}_{2.5}$ over the STN and IMPROVE sites from all simulations could also be due to the underprediction of precipitation, which leads to less scavenging and wet deposition of $\mathrm{PM}_{2.5}$. Over Beijing and Japan, model perfor- mance of simulations with dust treatments is more comparable with both DEFAULT CMAQ v4.7 and CMAQ v4.4 for most of gaseous species. The NMBs for $\mathrm{NO}_{2}$ over Beijing and $\mathrm{CO}, \mathrm{SO}_{2}$, nitric oxide (NO), and $\mathrm{NO}_{2}$ over Japan are $-71.9 \%,-58.7 \%,-35.5 \%,-91.1 \%$ and $-64.3 \%$, respectively for simulation DUST, indicating a significant underestimation of emissions for those species over Asia. For $\max 1 \mathrm{~h} \mathrm{O}$, DUST gives better agreement with observations than the DEFAULT CMAQ v4.7 with NMBs of $13.7 \%$ vs. $17.3 \%$, due to the heterogeneous uptake of $\mathrm{O}_{3}$. For $\mathrm{PM}_{10}$ and suspended particulate matter (SPM), the model performance of the simulation DUST is much better compared with DEFAULT CMAQ v4.7 and CMAQ v4.4 (NMBs of $-45.8 \%$ vs. $-80.9 \%$ and $-83.6 \%$ for $\mathrm{PM}_{10}$ and $-34.7 \%$ vs. $-50.9 \%$ and $-49.7 \%$ for SPM, respectively) due to the contribution of dust particles. However, underpredictions remain, indicating that the dust emissions might be underestimated over the deserts in China. This finding is consistent with the analysis in Sect. 4.2.1. The performance of $\mathrm{PM}_{10}$ and SPM is further improved in simulation DUST_HIGH_EF (e.g., NMBs of $-10.3 \%$ for $\mathrm{PM}_{10}$ and $-18.2 \%$ for SPM) over East Asia, despite worse overpredictions in $\mathrm{PM}_{2.5}$ concentrations and visibility indices. 


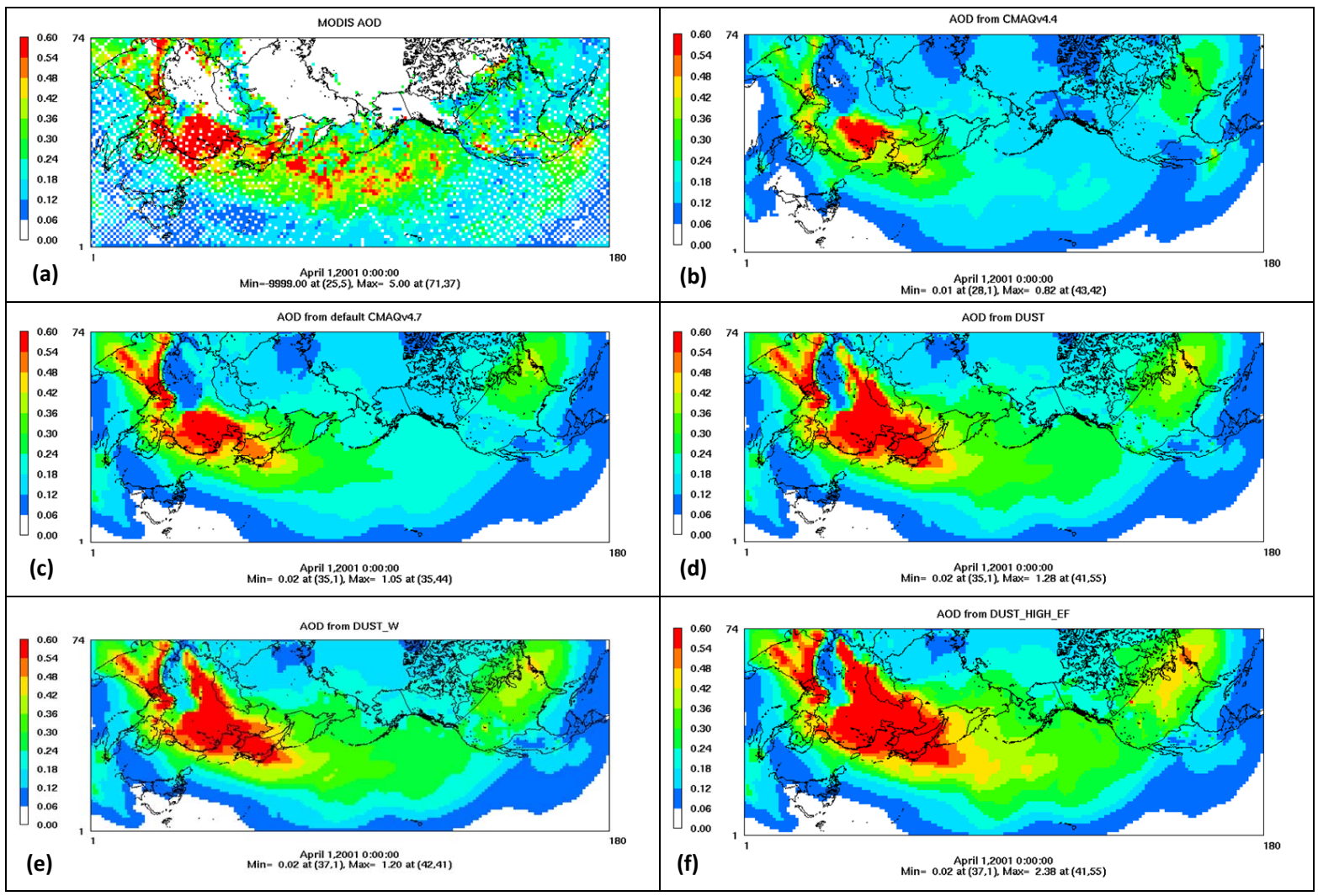

Fig. 2. Spatial distribution of AOD from (a) MODIS observations and simulations (b) CMAQ v4.4, (c) DEFAULT CMAQ v4.7, (d) DUST , (e) DUST_W, and (f) DUST_HIGH_EF in April 2001.

Figures S-4 and 2 show the spatial distribution of column variables from satellite observations, CMAQ v4.4, DEFAULT CMAQ v4.7, DUST, DUST_W, and DUST_HIGH_EF in April 2001. Table 8 summarizes the corresponding performance statistics. The simulation DUST predicts the columns $\mathrm{CO}$, TOR, and $\mathrm{NO}_{2}$ quite well with NMBs of $-9.0 \%,-17.2 \%$, and $10.0 \%$, respectively, and shows a very similar pattern compared with the simulation DEFAULT CMAQ v4.7. The correlation coefficients are also high for all three column variables. Compared with CMAQ v4.4, DEFAULT CMAQ v4.7 and DUST give the comparable performance for $\mathrm{NO}_{2}$, slightly better performance for column $\mathrm{CO}$, and considerable performance improvement for TOR due to the use of the CB05 mechanism. More importantly, the dust treatments in simulations DUST, DUST_W, and DUST_HIGH_EF greatly improve AOD predictions, especially over the Pacific Ocean, with the domain-wide NMB reduced from $-35.4 \%$ (CMAQ v4.4) and $-20.2 \%$ (DEFAULT CMAQ v4.7) to $-7.8 \%$ (DUST), $-7.7 \%$ (DUST_W), and $7.3 \%$ (DUST_HIGH_EF). Figure 3 compares temporal variations of observed daily average column AODs from AERONET and derived values from three CMAQ-Dust simulations at four AERONET sites. The missing values for AERONET measurements are due to cloudi- ness. Three out of four sites (except for Beijing) are in rural areas and close to the dust source regions, where the influence from anthropogenic emissions is thus little and AODs are predominantly affected by natural aerosols such as dust particles. The temporal trend between simulation and observation is similar except for a few days. For example, on 28 April, the model overpredicts AOD in Dunhuang and Inner Mongolia, while underpredictions occur in Beijing. Considering the large uncertainties associated with dust emissions and model treatments in WRF and CMAQ v4.7, the agreement between observed and simulated AOD is reasonably good, demonstrating the ability of CMAQ-Dust in capturing both the spatial patterns and the day-to-day variations of aerosols including dust particles.

\section{Impacts of dust treatments}

Given the superior performance of the Zender scheme, it is selected to perform several additional simulations to investigate the impacts of dust treatments in this section. 


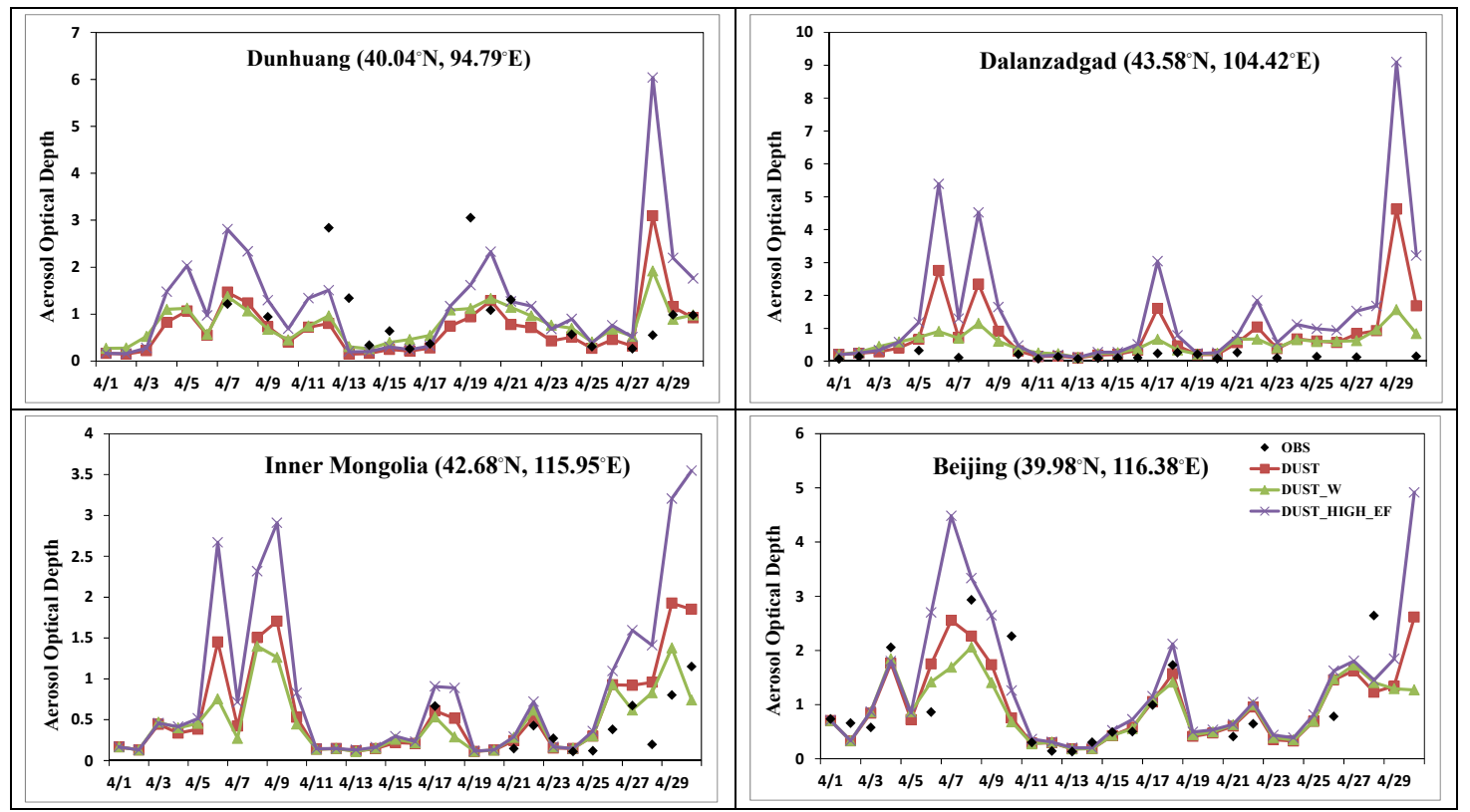

Fig. 3. Temporal variation of daily average AOD from AERONET observations, simulations DUST, DUST_W, and DUST_HIGH_EF during April 2001 at four AERONET sites.

Table 8. Performance statistics for column predictions over the ICAP domain in April 2001.

\begin{tabular}{llrrrr}
\hline & Variables & $\mathrm{CO}$ & $\mathrm{TOR}$ & $\mathrm{NO}_{2}$ & $\mathrm{AOD}$ \\
\hline & Data Number & 16048 & 7900 & 36760 & 12387 \\
& Mean Obs. & 2.41 & 36.0 & 8.7 & 0.27 \\
\hline MM5/CMAQ & Mean Pred. & 2.14 & 26.6 & 8.4 & 0.18 \\
v4.4 & Correlation & 0.47 & 0.56 & 0.86 & 0.61 \\
& NMB (\%) & -11.0 & -26.1 & -3.9 & -35.4 \\
& NME (\%) & 15.1 & 26.6 & 43.5 & 41.2 \\
\hline DEFAULT & Mean Pred. & 2.19 & 29.9 & 9.4 & 0.22 \\
CMAQ v4.7 & Correlation & 0.55 & 0.65 & 0.85 & 0.63 \\
& NMB (\%) & -9.0 & -16.9 & 8.6 & -20.2 \\
& NME (\%) & 12.9 & 18.5 & 48.2 & 34.8 \\
\hline DUST & Mean Pred. & 2.19 & 29.8 & 9.6 & 0.25 \\
& Correlation & 0.55 & 0.65 & 0.85 & 0.63 \\
& NMB (\%) & -9.0 & -17.2 & 10.0 & -7.8 \\
& NME (\%) & 12.9 & 18.6 & 48.6 & 34.6 \\
\hline DUST_W & Mean Pred. & 2.19 & 29.8 & 9.6 & 0.25 \\
& Correlation & 0.55 & 0.65 & 0.85 & 0.64 \\
& NMB (\%) & -9.0 & -17.3 & 10.0 & -7.7 \\
& NME (\%) & 12.9 & 18.7 & 48.6 & 34.3 \\
\hline DUST_HIGH_EF & Mean Pred. & 2.19 & 29.6 & 9.6 & 0.29 \\
& Correlation & 0.55 & 0.65 & 0.85 & 0.61 \\
& NMB (\%) & -9.0 & -17.8 & 10.3 & 7.3 \\
& NME (\%) & 13.0 & 19.1 & 48.4 & 39.8 \\
\hline
\end{tabular}

\subsection{Importance of crustal species}

Crustal species can profoundly affect gas/particle partitioning into both fine and coarse modes of PM (e.g., Jacobson, 1997; Fountoukis et al., 2009). Figures 4 and 5 show the spatial distribution of differences between simulations CRUST_ONLY and DUST_EMIS_ONLY for surface layer concentrations of gases including $\mathrm{SO}_{2}, \mathrm{NH}_{3}, \mathrm{HNO}_{3}$ and aerosols including $\mathrm{PM}_{2.5}, \mathrm{PM}_{\text {coarse }}$, and their compositions such as $\mathrm{SO}_{4}^{2-}, \mathrm{NO}_{3}^{-}, \mathrm{NH}_{4}^{+}$, and $\mathrm{Cl}^{-}$in April 2001. For nonreactive species such as $\mathrm{EC}, \mathrm{OC}$, and other inorganic aerosols (OIN) (figures not shown here), two simulations show very small differences (generally $< \pm 0.01 \mu \mathrm{g} \mathrm{m}^{-3}$ ). Compared with DUST_EMIS_ONLY, CRUST_ONLY predicts relatively lower $\mathrm{SO}_{4}^{2-}$ (about $0.1 \mathrm{\mu g} \mathrm{m}^{-3}$ ) over East Asia, due to less oxidation of $\mathrm{SO}_{2}$ to form sulfuric acid $\left(\mathrm{H}_{2} \mathrm{SO}_{4}\right)$. The less oxidation is mainly due to the lower $\mathrm{H}_{2} \mathrm{O}_{2}$ and $\mathrm{O}_{3}$ mixing ratios predicted by CRUST_ONLY with ISORROPIA II, which is caused by the perturbation of the chemistry system through the impacts of crustal species on $\mathrm{NH}_{3}$ and $\mathrm{HNO}_{3}$. For volatile species such as $\mathrm{NO}_{3}^{-}$and $\mathrm{NH}_{4}^{+}$, the effects of crustal species are much more significant. The addition of crustal species decreases the predicted concentrations of finemode $\mathrm{NH}_{4}^{+}$throughout the domain, which indicates a charge balance effect (i.e., $\mathrm{NH}_{4}^{+}$is replaced by crustal species such as $\mathrm{Ca}^{2+}$ ) and is consistent with results using the thermodynamic equilibrium box models (e.g., Wang et al., 2006; Fountoukis et al., 2009; Wang, 2011). On the other hand, the impact of crustal species on $\mathrm{NO}_{3}^{-}$is more complicated with the enhancement of fine-mode $\mathrm{NO}_{3}^{-}$concentrations over dust 


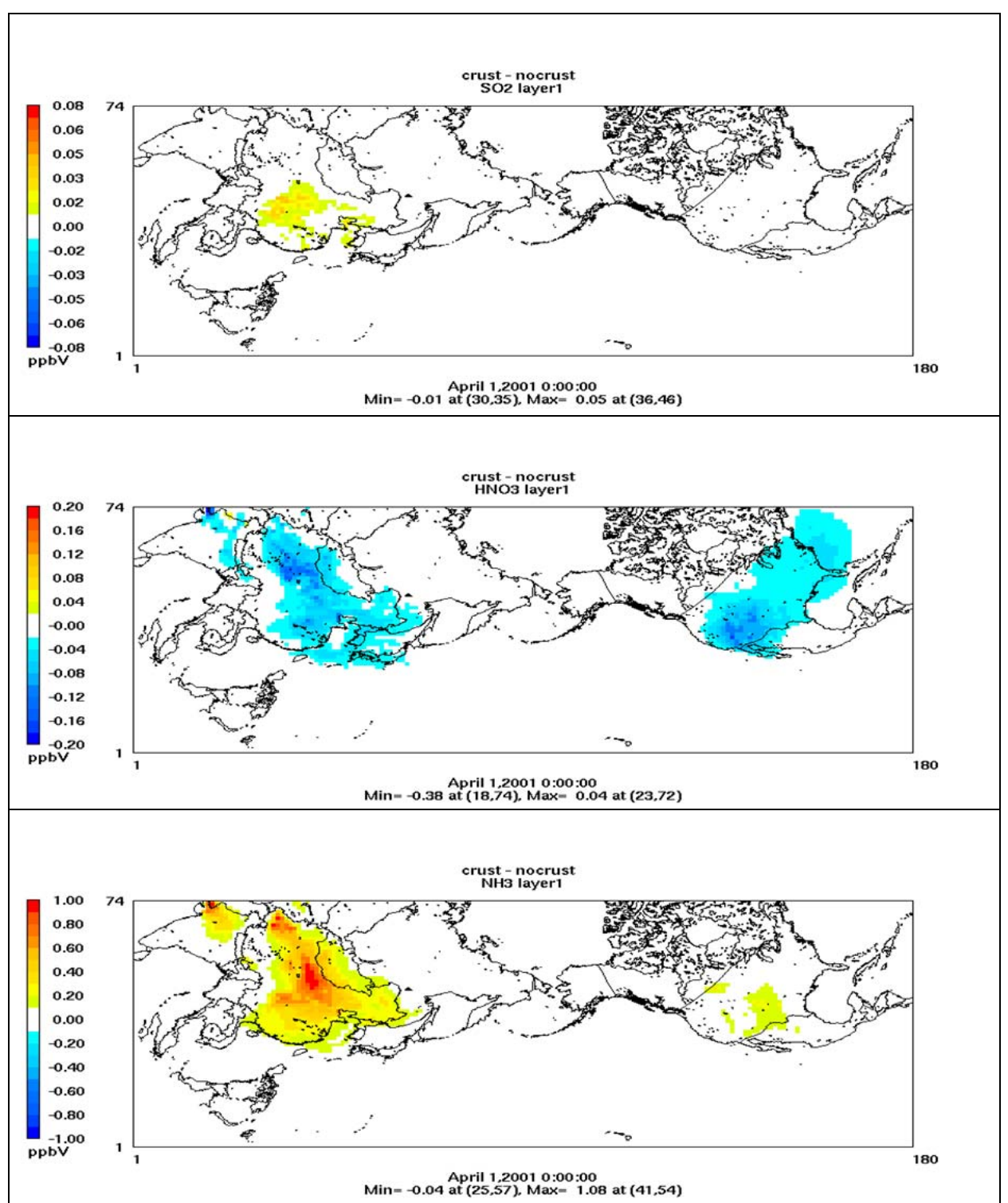

Fig. 4. Spatial distribution of differences between simulations CRUST_ONLY and DUST_EMIS_ONLY for surface layer $\mathrm{SO}_{2}, \mathrm{HNO}_{3}$, and $\mathrm{NH}_{3}$ in April 2001; this figure illustrates the effects of crustal species.

source regions and reduction over downwind heavily polluted areas such as the Eastern China and Northern India. The increase of $\mathrm{NO}_{3}^{-}$can be explained (under neutral aerosol conditions) by the formation of deliquescent salts (e.g., through the reaction of crustal cations with $\mathrm{NO}_{3}^{-}$). Decreases in $\mathrm{NO}_{3}^{-}$ may arise from "activity effect" of crustal ions (Jacobson, 1999), where dissolved crustal ions may considerably increase the activity coefficient of ammonium nitrate and force it to repartition to the gas phase. Another factor is the repartitioning of fine-mode $\mathrm{NO}_{3}^{-}$into the coarse-mode, where most of the crustal species reside. Figures 6 and $7 \mathrm{a}-\mathrm{b}$ show clearly that the inclusion of crustal species tends to shift $\mathrm{NO}_{3}^{-}$from fine-mode into coarse-mode over the polluted areas. This is in agreement with Karydis et al. (2010), who applied the Comprehensive Air-quality Model with PM treatments over the high dust concentration area of Mexico City and found a significant shift of predicted $\mathrm{NO}_{3}^{-}$from fine-mode to coarsemode with the explicit treatment of crustal species. Finemode $\mathrm{Cl}^{-}$shows a similar decrease pattern as $\mathrm{NO}_{3}^{-}$over the East Asia. The mixing ratios of gas-phase $\mathrm{NH}_{3}$ and $\mathrm{HNO}_{3}$ are increased and decreased, respectively, as expected according to the mass balance. Finally, the reaction of $\mathrm{Ca}^{2+}$ with $\mathrm{SO}_{4}^{2-}$ can reduce the amount of aerosol liquid water (by converting soluble $\mathrm{SO}_{4}^{2-}$ or Ca salts into sparsely soluble $\mathrm{CaSO}_{4}$ ), and shift nitrate partitioning to the gas phase. When all these mechanisms are combined, the inclusion of crustal 


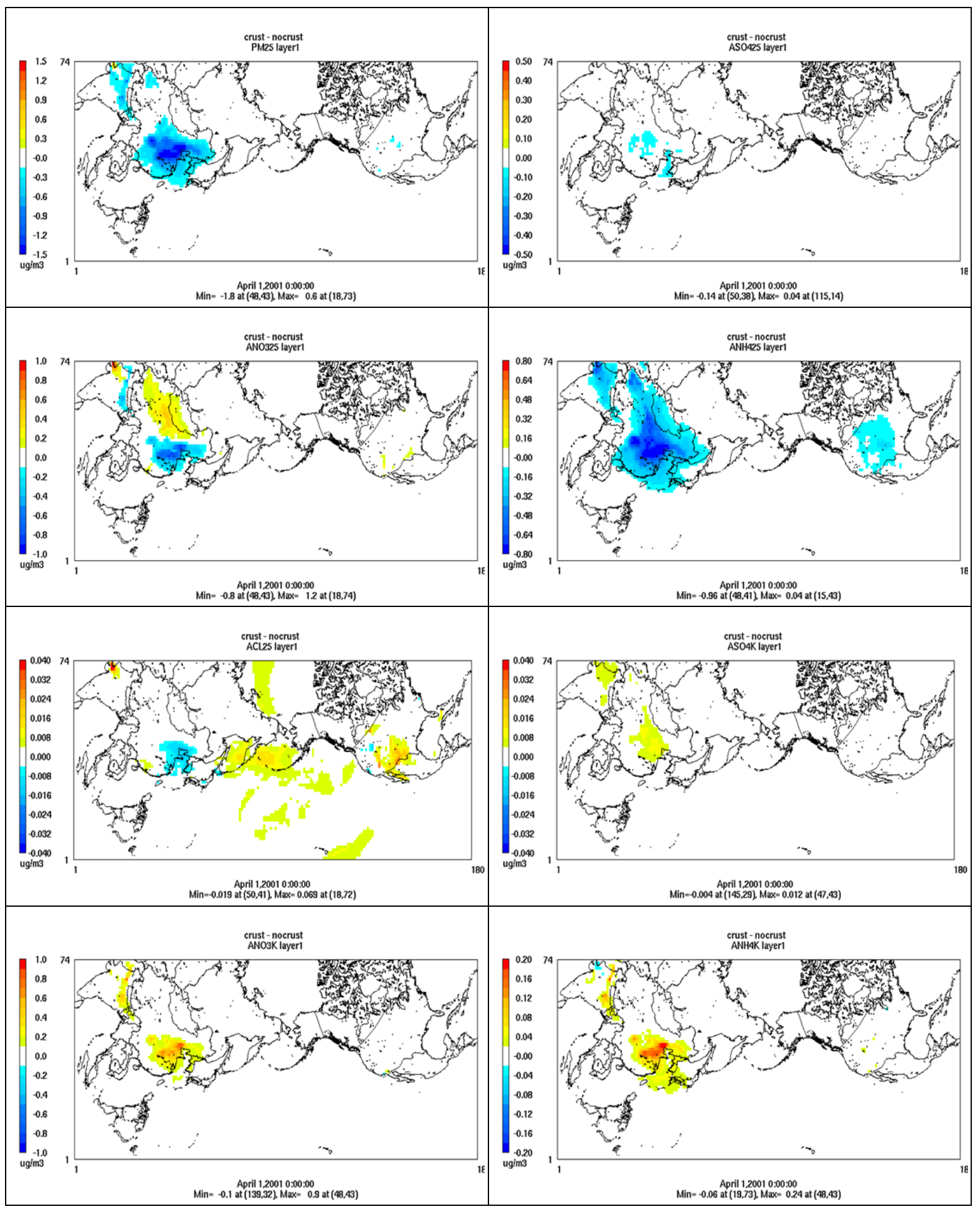

Fig. 5. Spatial distribution of differences between simulations CRUST_ONLY and DUST_EMIS_ONLY for surface layer PM 2.5 , fine-mode $\mathrm{SO}_{4}^{2-}, \mathrm{NO}_{3}^{-}, \mathrm{NH}_{4}^{+}$and $\mathrm{Cl}^{-}$, and coarse-mode $\mathrm{SO}_{4}^{2-}, \mathrm{NO}_{3}^{-}$and $\mathrm{NH}_{4}^{+}$in April 2001; this figure illustrates the effects of crustal species. 


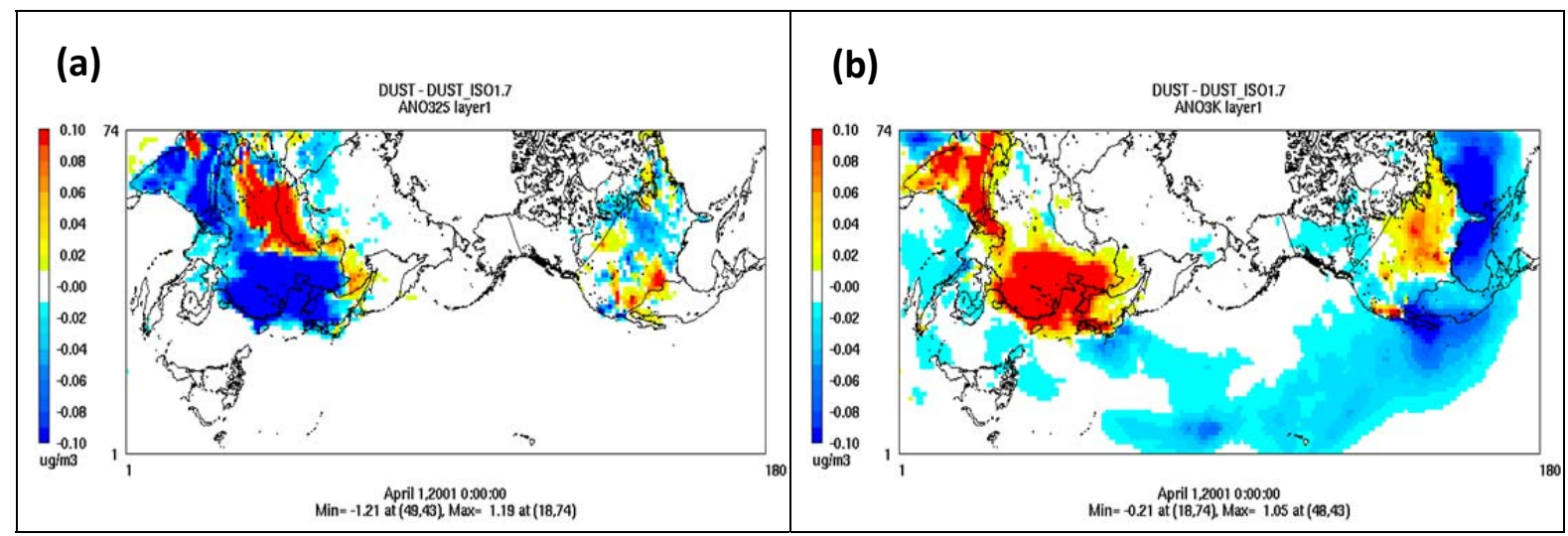

Fig. 6. Spatial distribution of differences between simulations DUST and DUST_ISO1.7 for $\mathrm{NO}_{3}^{-}$in (a) fine-mode and (b) coarse-mode in April 2001; this figure illustrates the effects of crustal species when dust heterogeneous chemistry is also treated.

species tends to reduce aerosol $\mathrm{NO}_{3}^{-}, \mathrm{NH}_{4}^{+}$and $\mathrm{PM}_{2.5}$ over East Asia.

\subsection{Impact of heterogeneous chemistry}

Heterogeneous chemistry on the surface of dust affects the concentrations of gases and PM. Figure 7 shows the spatial distribution of differences between the simulations DUST and CRUST_ONLY and between the simulations DUST_HIGH_UPTAKE and CRUST_ONLY for surface layer $\mathrm{O}_{3}, \mathrm{NO}_{\mathrm{x}}, \mathrm{H}_{2} \mathrm{O}_{2}$, and $\mathrm{NO}_{3}^{-}$and $\mathrm{PM}_{2.5}$ in April 2001. The mixing ratios of $\mathrm{O}_{3}$ and several other species such as $\mathrm{SO}_{2}, \mathrm{~N}_{2} \mathrm{O}_{5}$, and $\mathrm{HO}_{\mathrm{x}}$ (figures for other species not shown) are reduced in the presence of dust due to irreversible uptakes. The spatial distribution of $\mathrm{O}_{3}$ reduction corresponds well with the dust distribution shown in Fig. 1. The decrease of monthly average surface $\mathrm{O}_{3}$ mixing ratios can be up to $3.8 \mathrm{ppb}(\sim 9 \%)$ from DUST and $7.3 \mathrm{ppb}(\sim 15 \%)$ from DUST_HIGH_UPTAKE over the dust source region, which is comparable to those reported by previous studies (Dentener et al., 1996; Tang et al., 2004; Pozzoli et al., 2008a). The decrease of $\mathrm{SO}_{2}$ mixing ratios can be up to $\sim 0.3$ and $0.6 \mathrm{ppb}$ from the two simulations, respectively $(\sim 5$ to $8 \%$ over the polluted areas and 27 to $34 \%$ over the dust source regions). Different from other gases, the mixing ratios of $\mathrm{NO}_{\mathrm{x}}$ in the simulation DUST increase due to renoxification that converts $\mathrm{HNO}_{3}$ back to $\mathrm{NO}_{\mathrm{x}}$ at the surface of dust, with the largest increase over the Eastern China where $\mathrm{NO}_{\mathrm{x}}$ emissions are the highest. The small decrease in the mixing ratios of $\mathrm{HNO}_{3}$ is unexpected (as shown in Fig. S-5), since the increase of $\mathrm{NO}_{\mathrm{x}}$ indicates the heterogeneous uptake of $\mathrm{HNO}_{3}$ is significant and should have resulted in lower levels of gasphase $\mathrm{HNO}_{3}$. Therefore, there must be some other mechanisms that also generate $\mathrm{HNO}_{3}$ to compensate the decrease of $\mathrm{HNO}_{3}$ via heterogeneous chemistry. The small decrease of both fine- and coarse-mode $\mathrm{NO}_{3}^{-}$suggests evaporation of $\mathrm{NO}_{3}^{-}$from the particulate phase. The evaporation of $\mathrm{NO}_{3}^{-}$is due to the fact that the addition of a large amount of $\mathrm{SO}_{4}^{2-}$ generated by heterogeneous uptake alternates the chemical regime of aerosols and then replaces $\mathrm{NO}_{3}^{-}$as ions (e.g., replacing $\mathrm{NH}_{4} \mathrm{NO}_{3}$ as $\left.\left(\mathrm{NH}_{4}\right)_{2} \mathrm{SO}_{4}\right)$ over the domain. The mass balance analysis of total nitrate (i.e., the sum of $\mathrm{HNO}_{3}$ and $\mathrm{NO}_{3}^{-}$) also shows a more significant decrease trend (figure not shown) that can help explain the unexpected pattern of $\mathrm{HNO}_{3}$. The decreases of both $\mathrm{NO}_{3}$ and $\mathrm{N}_{2} \mathrm{O}_{5}$ mixing ratio are relatively small compared with other species mainly due to their less abundance in the atmosphere. $\mathrm{H}_{2} \mathrm{O}_{2}$ mixing ratio is increased in the simulation DUST, owing to the heterogeneous uptake on the dust particles that converts $\mathrm{HO}_{2}$ to $\mathrm{H}_{2} \mathrm{O}_{2}$ and much less uptake of $\mathrm{H}_{2} \mathrm{O}_{2}$ itself, as compared with the simulation DUST_HIGH_UPTAKE. This conversion leads to a reduction of $\mathrm{HO}_{\mathrm{x}}$ mixing ratio in the simulation DUST by up to $8 \mathrm{ppt}(80 \%)$ over the dust source regions and by up to $2 \mathrm{ppt}$ (20 to $30 \%$ ) over the downwind polluted areas, consistent with the $\mathrm{HO}_{\mathrm{x}}$ decrease reported by Bian and Zender (2003).

The surface layer concentrations of $\mathrm{PM}_{2.5}$ and $\mathrm{PM}_{\text {coarse }}$ increase in the simulation DUST, which can be mainly attributed to an increase in $\mathrm{SO}_{4}^{2-}$ concentrations by up to 1.1 and $0.12 \mu \mathrm{g} \mathrm{m}^{-3}(12 \%$ and $>100 \%)$ in fine- and coarsemode (figures for $\mathrm{PM}_{\text {coarse }}$ and $\mathrm{SO}_{4}^{2-}$ not shown), respectively, due to the $\mathrm{SO}_{2}$ heterogeneous reaction with dust particles over the heavily polluted areas such as the Eastern China and Northern India. The larger percentage increase in the concentrations of coarse-mode $\mathrm{SO}_{4}^{2-}$ is because they are very small in the absence of dust. The increase in concentrations of $\mathrm{SO}_{4}^{2-}$ leads to an increase in the $\mathrm{NH}_{4}^{+}$concentrations (figure not shown) due to the charge balance effect. The overall effect of heterogeneous reactions on $\mathrm{NO}_{3}^{-}$ in the simulation DUST is small and much lower than that reported by Tang et al. (2004) and Bauer et al. (2004), partly due to the competition effect of $\mathrm{SO}_{4}^{2-}$ discussed above. Another reason may be due to the lower $\gamma$ values used in the simulation DUST (e.g., 0.001 versus 0.1 or 0.01 for $\mathrm{HNO}_{3}$, 


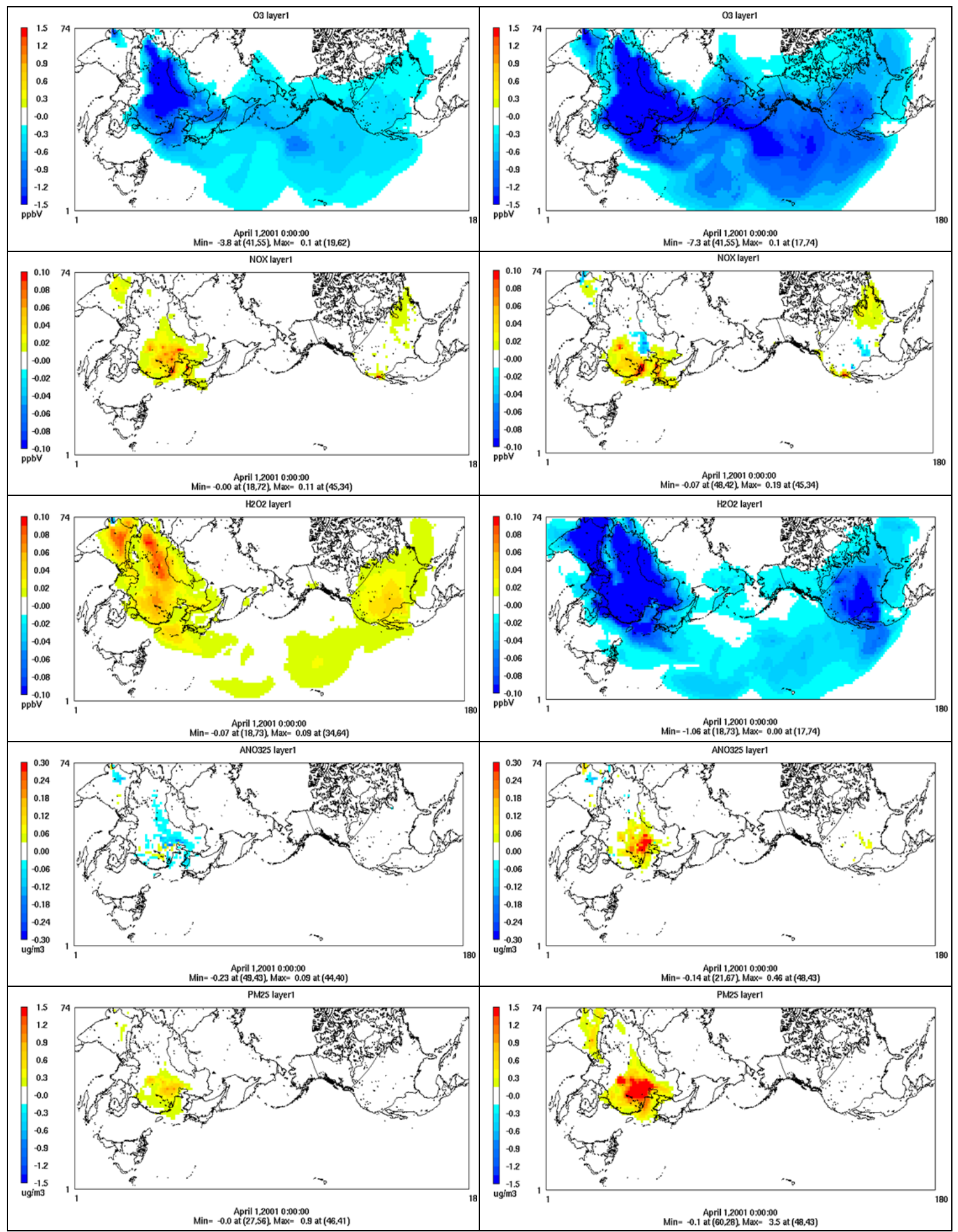

Fig. 7. Spatial distribution of differences between simulations DUST and CRUST_ONLY (left panel) and between DUST_HIGH_UPTAKE and CRUST_ONLY (right panel) for surface layer $\mathrm{O}_{3}, \mathrm{NO}_{\mathrm{x}}, \mathrm{H}_{2} \mathrm{O}_{2}$, fine-mode $\mathrm{NO}_{3}^{-}$, and $\mathrm{PM}_{2.5}$ in April 2001; this figure illustrates a lower and upper bound of the effects of dust heterogeneous chemistry. 
$4.4 \times 10^{-5}$ versus $1.0 \times 10^{-4}$ for $\mathrm{NO}_{2}$, and 0.001 versus 0.02 for $\mathrm{N}_{2} \mathrm{O}_{5}$ ), compared to the values used by Tang et al. (2004) and Bauer et al. (2004). As also shown in Fig. 7, the simulation DUST_HIGH_UPTAKE with upper limit $\gamma$ values causes much greater changes in most of these species than those from DUST (e.g., much higher enhancement of $\mathrm{NO}_{3}^{-}$ concentrations).

\subsection{Impact of dust treatment on gas and PM levels}

Figures 8 and 9 show the spatial distribution of differences between simulations DUST and BASELINE_NO_DUST and between DUST_HIGH_EF and BASELINE_NO_DUST for several gaseous (i.e., $\mathrm{O}_{3}, \mathrm{NO}_{\mathrm{x}}, \mathrm{SO}_{2}, \mathrm{HNO}_{3}$, and $\mathrm{H}_{2} \mathrm{O}_{2}$ ) and aerosol species (i.e., fine-mode $\mathrm{SO}_{4}^{2-}$ and $\mathrm{NO}_{3}^{-}$, coarsemode $\mathrm{SO}_{4}^{2-}$ and $\mathrm{NO}_{3}^{-}$, and $\mathrm{PM}_{10}$ ), respectively, at the surface layer in April 2001. Similar plots for $\mathrm{PM}_{2.5}$ and $\mathrm{PM}_{\text {coarse }}$ are shown in Fig. S-6. The surface monthly mean mixing ratios of $\mathrm{O}_{3}$ and $\mathrm{SO}_{2}$ are reduced and the mixing ratio of $\mathrm{H}_{2} \mathrm{O}_{2}$ is increased with all dust treatments and distributions for those species correspond well with those shown in Fig. 7, indicating dominant influences from heterogeneous chemistry. The increase of $\mathrm{NO}_{\mathrm{x}}$ over most of the domain is due to the renoxification process as discussed in Sect. 5.2. The impact of dust treatment on the spatial pattern of $\mathrm{HNO}_{3}$ is dominated by the effects from $\mathrm{HNO}_{3} / \mathrm{NO}_{3}^{-}$partitioning. As shown in Fig. 9, the increase of surface concentrations for $\mathrm{SO}_{4}^{2-}$ (both fine- and coarse-mode) over Asia with the dust treatment is mainly due to heterogeneous chemistry and the decrease over Pacific and Atlantic Ocean and the Northeastern US is due to the less production of $\mathrm{H}_{2} \mathrm{SO}_{4}$ from the gas-phase oxidation as a result of reduced $\mathrm{HO}_{\mathrm{x}}$ that dominates over the effect of heterogeneous chemistry. For those volatile species (i.e., $\mathrm{NO}_{3}^{-}$and $\mathrm{NH}_{4}^{+}$), the differences between the simulations DUST (or DUST_HIGH_EF) and BASELINE_NO_DUST are determined mainly by the effects of crustal species. The overall impact of dust treatments on $\mathrm{PM}_{10}$ is large. For example, DUST predicts the concentration enhancements of up to $\sim 1780$ and $5 \mu \mathrm{g} \mathrm{m}^{-3}$ for $\mathrm{PM}_{10}$ over the dust source regions and the Pacific and Atlantic Ocean, respectively. DUST_HIGH_EF predicts much greater $\mathrm{PM}_{10}$ concentration enhancements of up to 3560 and $10 \mu \mathrm{g} \mathrm{m}^{-3}$ over the dust source regions and the Pacific and Atlantic Ocean, respectively.

Similar plots for $\mathrm{O}_{3}, \mathrm{SO}_{2}$, total $\mathrm{SO}_{4}^{2-}$, total $\mathrm{NO}_{3}^{-}$, and $\mathrm{PM}_{10}$ are shown at an altitude of $5 \mathrm{~km}$ in Fig. 10. Those for $\mathrm{PM}_{2.5}$ and $\mathrm{PM}_{\text {coarse }}$ are shown in Fig. S-7. In contrast to the distribution in the surface layer, the decrease of $\mathrm{O}_{3}$ at $5 \mathrm{~km}$ altitude is more pronounced in the downwind/remote areas instead of dust source regions. This finding reflects that sufficient amounts of dust particles have been transported efficiently to the remote areas and have become aged to provide larger surface sites than freshly emitted particles for heterogeneous uptake of $\mathrm{O}_{3}$ at higher altitudes. The similar patterns are also found for $\mathrm{SO}_{2}$ and $\mathrm{HNO}_{3}$. By contrast, the impacts of dust treatments on $\mathrm{NO}_{\mathrm{x}}$ and $\mathrm{HO}_{\mathrm{x}}$ (figures not shown) are much smaller at higher altitudes, indicating less abundance of those species due to their short lifetimes. For the PM species, the impacts of dust treatments are also more pronounced at $5 \mathrm{~km}$ altitude over many areas far from dust source regions, indicating more efficient uptake of precursors on aged dust particles (Fairlie et al., 2010). The concentration enhancement of $\mathrm{PM}_{10}$ due to dust treatments at higher altitudes is much larger over the downwind and remote areas (up to $\sim 25 \mu \mathrm{g} \mathrm{m}^{-3}$ over the Pacific Ocean from DUST and up to $\sim 50 \mu \mathrm{g} \mathrm{m}^{-3}$ from DUST_HIGH_UPTAKE), indicating more efficient transport at higher altitudes.

\subsection{Impact of Asian pollution on the US air quality with dust treatments}

The enhancements of both gaseous and aerosol species over the US in the presence of dust are quantified by calculating the differences between the DUST and DUST_NO_ASIA_EMIS simulations (Fig. 11). As expected, the Western US receives much higher influx of air pollutants from the trans-Pacific transport than the Eastern US. The simulated surface concentrations of $\mathrm{O}_{3}$ and $\mathrm{CO}$ increase by $\sim 1.5 \mathrm{ppb}(3.6 \%)$ and $\sim 2.5 \mathrm{ppb}(2.1 \%)$, respectively over the Western US. The enhancement for $\mathrm{SO}_{2}$ and $\mathrm{NO}_{\mathrm{y}}$ is much higher over the Western US than the Eastern US. Compared with other gases, $\mathrm{NO}_{\mathrm{x}}$ shows a different pattern over the entire US with a negative contribution of Asian anthropogenic emissions to the $\mathrm{NO}_{\mathrm{x}}$ mixing ratios in the US. Wang et al. (2009) found that the direct long-range transport of $\mathrm{NO}_{\mathrm{x}}$ to the US is negligible. Therefore, the negative change of $\mathrm{NO}_{\mathrm{x}}$ as a result of the removal of Asian anthropogenic emissions is not due to the transport itself but to the differences in the rates of chemical destruction between the simulations with and without Asian anthropogenic emissions (i.e., less conversion of $\mathrm{NO}_{\mathrm{x}}$ to its sink such as $\mathrm{HNO}_{3}, \mathrm{PAN}$, or $\mathrm{N}_{2} \mathrm{O}_{5}$ when removing Asian anthropogenic emissions) in the US. The concentration enhancements of $\mathrm{SO}_{4}^{2-}$ and $\mathrm{NH}_{4}^{+}$(both by $\sim 20 \%$ for the Western US) dominate among the PM species, because $\left(\mathrm{NH}_{4}\right)_{2} \mathrm{SO}_{4}$ (and/or $\left.\mathrm{NH}_{4} \mathrm{HSO}_{4}\right)$ is the major aerosol component of trans-Pacific anthropogenic aerosols. The relative enhancement for OC in both the Western and Eastern US is higher than that of Wang et al. (2009) (i.e., 11 to $15 \%$ vs. 2 to $5 \%$ ), due to the updated SOA treatment in CMAQ v4.7. The relative enhancement for $\mathrm{PM}_{2.5}$ in the Western US is lower than that of Wang et al. (2009) (i.e., $\sim 5 \%$ vs. $\sim 10 \%$ ), which is mainly due to the inclusion of dust particles in $\mathrm{PM}_{2.5}$ that increases the baseline $\mathrm{PM}_{2.5}$ concentration significantly. In contrast with other PM species and the results of Wang et al. (2009), the $\mathrm{NO}_{3}^{-}$concentration is reduced in both the Eastern and Western US, due to two competitive effects driven by changes in emissions and thermodynamics when Asian emissions are removed. Removing Asian anthropogenic emissions of $\mathrm{NO}_{\mathrm{x}}$ and primary $\mathrm{NO}_{3}^{-}$directly reduces $\mathrm{NO}_{3}^{-}$concentrations in 


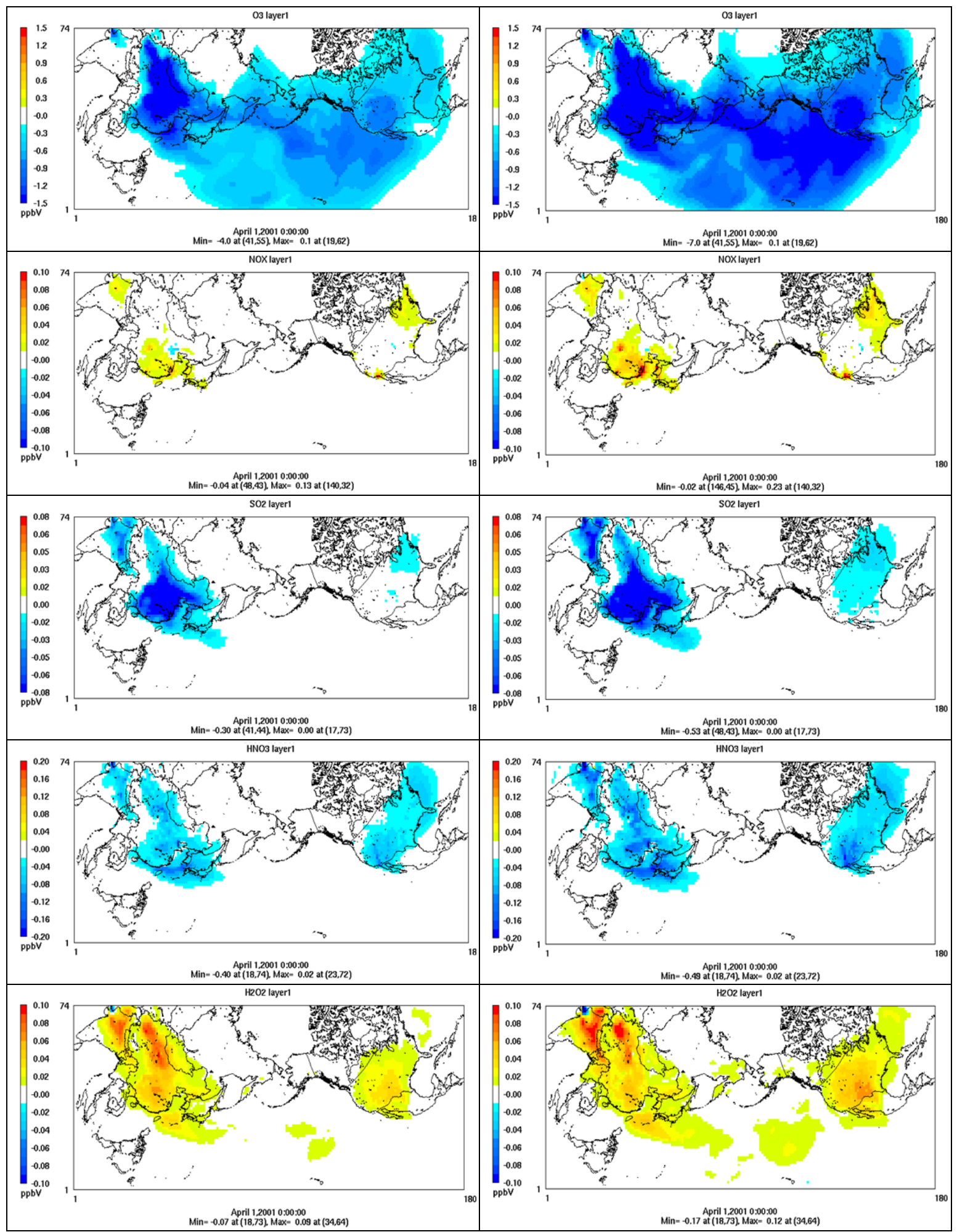

Fig. 8. Spatial distribution of differences between simulations DUST and BASELINE_NO_DUST (left panel) and between DUST_HIGH_EF and BASELINE_NO_DUST (right panel) at surface layer for $\mathrm{O}_{3}, \mathrm{NO}_{\mathrm{x}}, \mathrm{SO}_{2}, \mathrm{HNO}_{3}$, and $\mathrm{H}_{2} \mathrm{O}_{2}$ in April 2001; this figure illustrates a lower and upper bound of overall dust treatments in this study. 


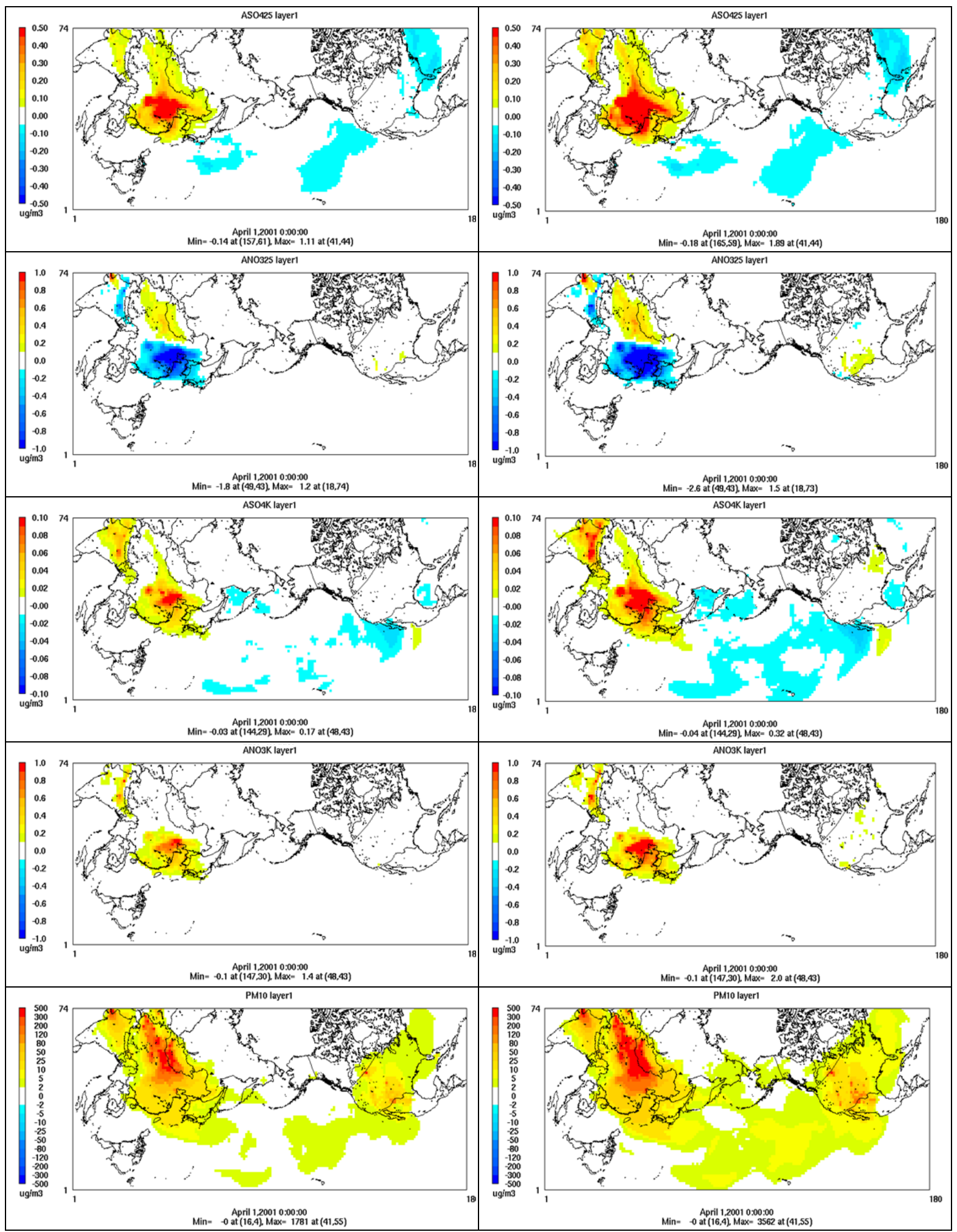

Fig. 9. Spatial distribution of differences between simulations DUST and BASELINE_NO_DUST (left panel) and between DUST_HIGH_EF and BASELINE_NO_DUST (right panel) at surface layer for fine-mode $\mathrm{SO}_{4}^{2-}$ and $\mathrm{NO}_{3}^{-}$, coarse-mode $\mathrm{SO}_{4}^{2-}$ and $\mathrm{NO}_{3}^{-}$, and $\mathrm{PM}_{10}$ in $\mathrm{April}^{-}$ 2001; this figure illustrates a lower and upper bound of overall dust treatments in this study. 


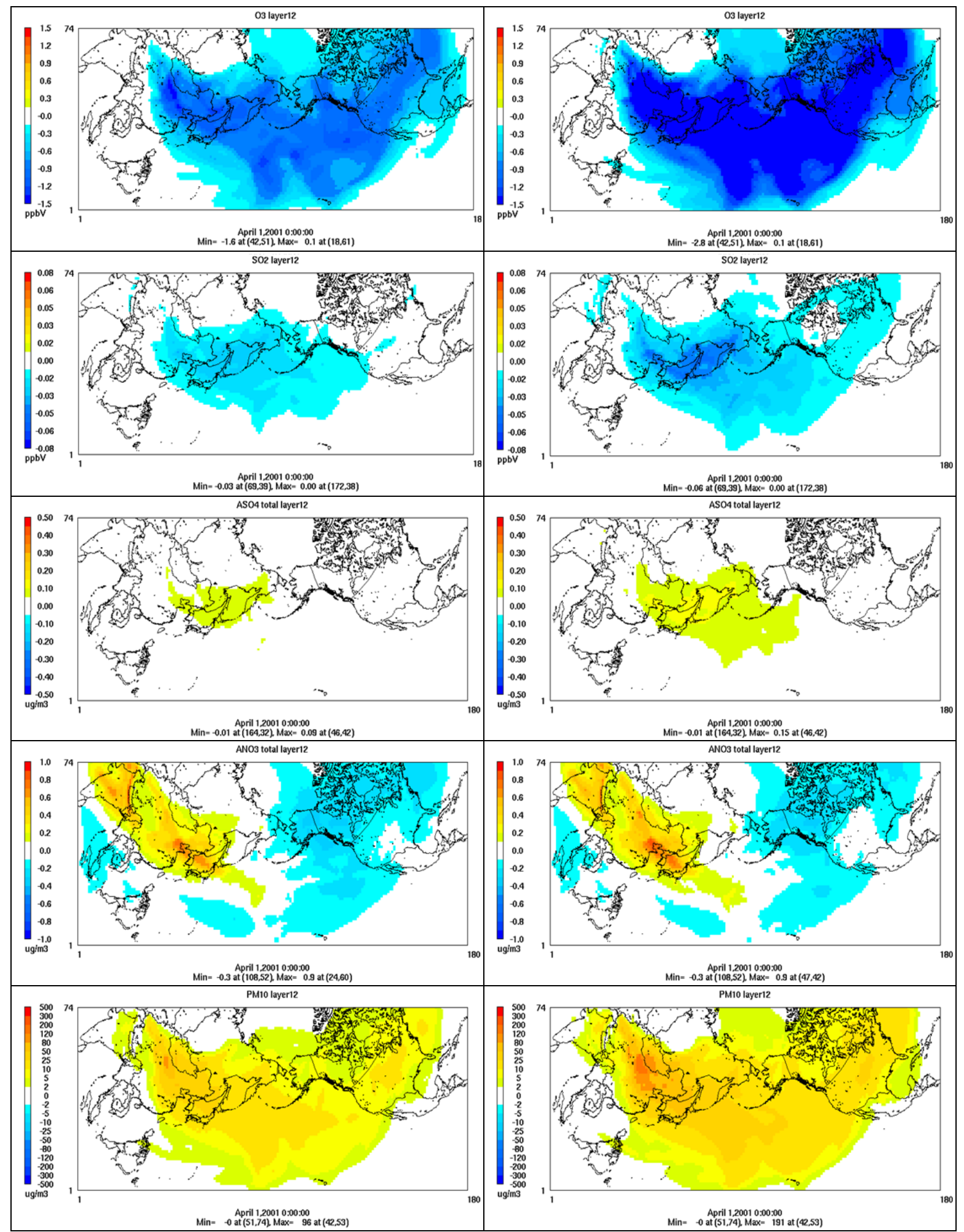

Fig. 10. Spatial distribution of differences between simulations DUST and BASELINE_NO_DUST (left panel) and between DUST_HIGH_EF and BASELINE_NO_DUST (right panel) at an altitude of $\sim 5 \mathrm{~km}$ for $\mathrm{O}_{3}, \mathrm{SO}_{2}$, total $\mathrm{SO}_{4}^{2-}$, total $\mathrm{NO}_{3}^{-}$, and $\mathrm{PM}_{10}$; this figure illustrates a lower and upper bound of overall dust treatments in this study. 


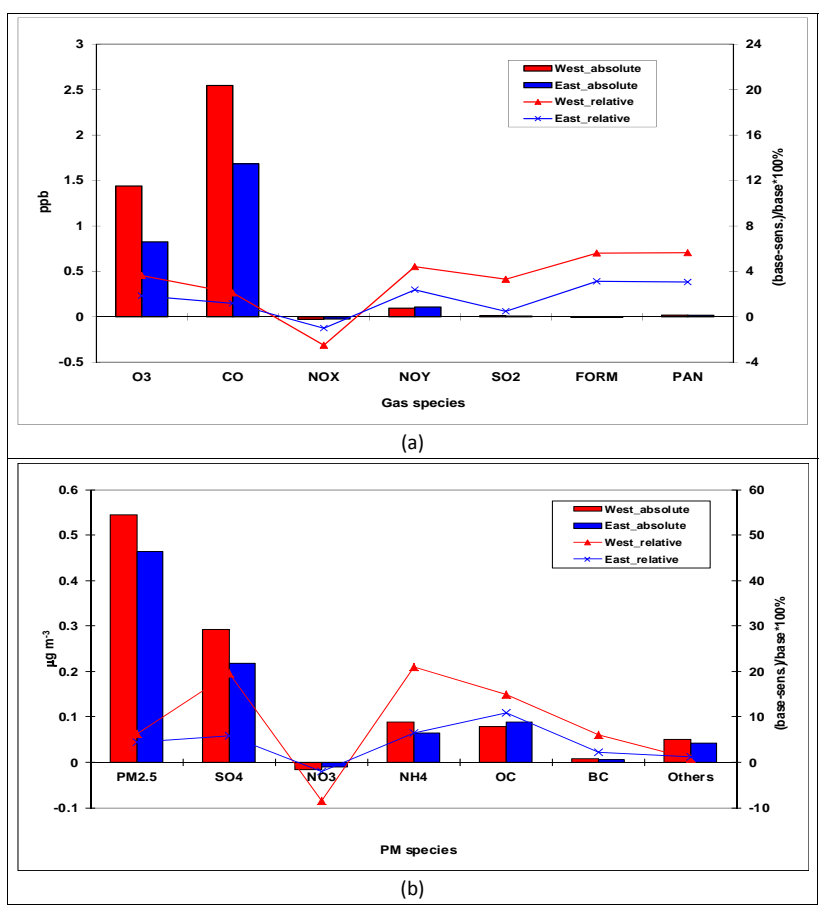

Fig. 11. Absolute and relative contributions of different (a) gaseous species and (b) $\mathrm{PM}_{2.5}$ components over the Western US and the Eastern US due to Asian anthropogenic emissions between simulations DUST and DUST_NO_ASIA_EMIS for April 2001.

the US in the simulation DUST_NO_ASIA_EMIS (referred to as the negative emission effect). Because of a stronger longrange transport of $\mathrm{SO}_{4}^{2-}$ than $\mathrm{NO}_{3}^{-}$, removing Asian anthropogenic emissions of $\mathrm{SO}_{2}$ and primary $\mathrm{SO}_{4}^{2-}$ also leads to much lower concentrations of $\mathrm{SO}_{4}^{2-}$ in the US, which triggers the changes in the aerosol thermodynamics. Compared with the simulation DUST, aerosols predicted from the simulation DUST_NO_ASIA_EMIS contain a similar level of crustal species but they are less acidic due to lower $\mathrm{SO}_{4}^{2-}$ concentrations (and to a lesser extent, lower $\mathrm{NO}_{3}^{-}$concentrations). Therefore, thermodynamics requires more $\mathrm{HNO}_{3}$ partitioning into the particulate phase to neutralize cations, increasing $\mathrm{NO}_{3}^{-}$concentrations (i.e., the positive thermodynamic effect). The positive thermodynamic effect dominates over the negative emission effect, leading to a net higher $\mathrm{NO}_{3}^{-}$concentration from the simulation DUST_NO_ASIA_EMIS than the simulation DUST.

\section{Conclusion and future work}

In this study, two established dust emission flux schemes and nine dust-related heterogeneous reactions are implemented into the US EPA's CMAQ v4.7 to enhance CMAQ's capability in simulating coarse PM and to examine the role of dust particles in affecting chemical predictions during the long- range transport. In addition, the default thermodynamic equilibrium module ISORROPIA v1.7 in CMAQ v4.7 is updated to ISORROPIA II to account for the impact of crustal species associated with dust particles on gas/particle partitioning. CMAQ with the new dust module is applied to the April 2001 dust storm episode over the trans-Pacific domain. The meteorological fields predicted by WRF 3.2 are first evaluated against the available observational data. WRF generally predicts well 2-m temperature and relative humidity and moderately overpredicts wind speed. WRF predicts precipitation relatively poorly compared to other variables which affects chemical predictions, especially $\mathrm{PM}_{2.5}$, via scavenging and wet deposition. CMAQ-Dust can reproduce concentrations of chemical species well. The model performance of CMAQ-Dust for $\mathrm{PM}_{10}$ and AOD is greatly improved as compared with that of the DEFAULT CMAQ v4.7 in this work and CMAQ v4.4 in Wang et al. (2009) due to the dust treatments implemented in this work.

The total simulated dust emissions by CMAQ-Dust are $\sim 111.4$ and $110.9 \mathrm{Tg}$ from Zender and Westphal schemes with an erodible fraction of 0.5 and can increase up to $\sim 223 \mathrm{Tg}$ with a higher fraction of 1.0 in the Zender scheme for April 2001, which is in line with other previous research over Asia. Using different erodible fractions, $E_{\mathrm{F}}$, of 0.5 and 1.0, the monthly mean surface total concentrations of dust particles predicted by CMAQ are generally $>200$ and $>500 \mu \mathrm{g} \mathrm{m}^{-3}$, respectively, over source regions in China and can reach up to 25 and $50 \mu \mathrm{g} \mathrm{m}^{-3}$, respectively, over the downwind areas such as the Eastern China, Japan, the Northeastern India, and the Midwest US. Long-range transport can increase surface total concentrations of dust by 5 to $10 \mu \mathrm{g} \mathrm{m}^{-3}$ over the remote regions such as the Eastern Pacific and the Eastern US. Both schemes predict similar total dust emissions with a similar spatial pattern and have similar CPU costs. However, the Zender scheme is more physically based and gives a better model performance than the Westphal scheme; it is therefore recommended for applications over regions with significant dust emissions.

A number of sensitivity simulations using the Zender scheme are conducted to investigate the effect of dust on the spatial distribution of various gaseous and PM species. The results show that the inclusion of crustal species tends to affect the volatile species (e.g., $\mathrm{NH}_{3}, \mathrm{NH}_{4}^{+}, \mathrm{HNO}_{3}$, and $\mathrm{NO}_{3}^{-}$) to a greater extent than other non-volatile species (e.g., $\mathrm{SO}_{4}^{2-}$ ). The effects include decreasing the fine-mode $\mathrm{NH}_{4}^{+}$ throughout the domain, increasing the fine-mode $\mathrm{NO}_{3}^{-}$over dust source regions but decreasing it over downwind heavily polluted areas, as well as shifting $\mathrm{NO}_{3}^{-}$from the fine-mode to the coarse-mode. The concentration of $\mathrm{PM}_{2.5}$ over the Eastern Asia is reduced due to the combined effect of crustal species on reducing $\mathrm{NO}_{3}^{-}$and $\mathrm{NH}_{4}^{+}$. Heterogeneous chemistry on dust particles tends to decrease the mixing ratio of $\mathrm{O}_{3}$ by up to $3.8 \mathrm{ppb}(\sim 9 \%)$ with $E_{\mathrm{F}}$ of 0.5 and $7.3 \mathrm{ppb}(\sim 15 \%)$ with $E_{\mathrm{F}}$ of 1.0 over the dust source regions, and to reduce 
$\mathrm{SO}_{2}$ mixing ratio by up to $0.3 \mathrm{ppb}(\sim 5 \%)$ with $E_{\mathrm{F}}$ of 0.5 and $0.6 \mathrm{ppb}(\sim 8 \%)$ with $E_{\mathrm{F}}$ of 1.0 over the polluted areas and up to $0.05 \mathrm{ppb}(\sim 27 \%)$ with $E_{\mathrm{F}}$ of 0.5 and $0.1 \mathrm{ppb}(\sim 34 \%)$ with $E_{\mathrm{F}}$ of 1.0 over the dust source regions. Different from other species, the mixing ratio of $\mathrm{NO}_{\mathrm{x}}$ increases throughout the domain due to the renoxification effect considered in the model. The decrease of $\mathrm{HNO}_{3}$ is not evident, indicating a compensation effect of the decrease of $\mathrm{HNO}_{3}$ by heterogeneous chemistry and the increase of $\mathrm{HNO}_{3}$ by evaporation of $\mathrm{NO}_{3}^{-}$particles caused by the increase of $\mathrm{SO}_{4}^{2-}$ concentrations. The heterogeneous uptakes play a more important role in $\mathrm{SO}_{4}^{2-}$ formation than other PM species. The concentrations of dust and their impacts at a higher altitude indicate the efficient long-range transport of dust and its active interactions with photochemical cycle and PM formation in upper troposphere and the remote areas. Such long-range transport contributes to the enhancement of the surface concentrations of various gaseous pollutants (e.g., $\mathrm{O}_{3}$ and $\mathrm{CO}$ ) by up to several ppb (up to $\sim 6 \%$ ) and $\mathrm{PM}$ species (e.g., $\mathrm{SO}_{4}^{2-}, \mathrm{NH}_{4}^{+}$, OC, and $\mathrm{PM}_{2.5}$ ) by up to $0.6 \mu \mathrm{g} \mathrm{m}^{-3}$ (up to $20 \%$ ) when $E_{\mathrm{F}}$ is assumed to be 0.5 .

Several uncertainties and limitations in the dust treatments exist in this study. For example, the parameter $E_{\mathrm{F}}$ is assumed to be constant everywhere. It mainly serves as a tuning factor without considering the spatial variability of the erodibility of the land. The crustal species are prescribed uniformly throughout the modeling domain. Their spatialvariability should be considered once such information becomes available, and predicted crustal materials should be evaluated against measurements over the source regions in China and from networks such as IMPROVE and STN in the downwind regions. The seasonal variations of vegetation coverage are not considered for dust emission calculation in this study, which could be important over some semiarid areas. As discussed in Sect. 2, the uptake coefficient of chemical species on the surface of dust has high uncertainties and may depend on the ambient conditions (e.g., temperature and relative humidity). Additional simulations may be performed using different sets of uptake coefficients such as those recommended by Crowly et al. (2010). Nevertheless, this work extends CMAQ's capability in simulating emissions and chemistry of mineral dust, which is a very important PM component in arid and semiarid areas. Its application to the April 2001 Asian dust event demonstrates the promising ability of CMAQ-Dust in capturing dust emissions, its concentrations and spatial variability, as well as the physical/chemical processes associated with dust particles. The dust treatments implemented in this work can be readily transferred into the latest version of CMAQ (i.e., CMAQ version 5).

\section{Supplementary material related to this article is

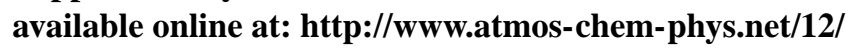 10209/2012/acp-12-10209-2012-supplement.pdf.}

Acknowledgements. This work was supported by the National Research Initiative Competitive Grant No. 2008-35112-18758 from the USDA Cooperative State Research, Education, and Extension Service Air Quality Program and the China's National Basic Research Program (2010CB951803). AN and CF acknowledge the support from the National Oceanic and Atmospheric Administration (NOAA) under contract NMRAC000-5-04017. Thanks are due to Carey Jang and Sharon Phillips, the US EPA, for providing the input files for the April 2001 ICAP testbed with MM5/CMAQv4.4; to Jack Fishman and his colleagues, NASA Langley Research Center, the US, for providing the TOMS/SBUV and MOPITT satellite data; to Ji-Ming Hao and Ke-Bin He, Tsinghua University, China, for providing the observational data in Beijing, China; to Takigawa Masayuki, the Frontier Research Center for Global Change, Japan, for providing the codes for the extraction of Japan data; to Shao-Cai Yu, the NOAA/US EPA, for providing Fortran codes for statistical calculations; NASA MODIS Adaptive Processing System, for providing MODIS AOD data; TEMIS of the European Space Agency for providing GOME $\mathrm{NO}_{2}$ data.

Edited by: G. Kallos

\section{References}

Astitha, M., Kallos, G., Spyrou, C., O'Hirok, W., Lelieveld, J., and Denier van der Gon, H. A. C.: Modelling the chemically aged and mixed aerosols over the eastern central Atlantic Ocean - potential impacts, Atmos. Chem. Phys., 10, 5797-5822, doi:10.5194/acp-10-5797-2010, 2010.

Bauer, S. E., Balkanski, Y., Schulz, M., Hauglustaine, D. A., and Dentener, F.: Global modeling of heterogeneous chemistry on mineral aerosol surfaces: Influence on tropospheric ozone chemistry and comparison to observations, J. Geophys. Res., 109, D02304, doi:10.1029/2003JD003868, 2004.

Bian, H. and Zender, C. S.: Mineral dust and global tropospheric chemistry: Relative roles of photolysis and heterogeneous uptake, J. Geophys. Res., 108, 4672, doi:10.1029/2002JD003143, 2003.

Burrows, J. P., Weber, M., Buchwitz, M., Rozanov, V., LadstatterWeibenmayer, A., Richter, A., DeBeek, R., Hoogen, R., Bramstedt, K., Eichmann, K.-U., and Eisinger, M.: The Global Ozone Monitoring Experiment (GOME): Mission concept and first scientific results, J. Atmos. Sci., 56, 151-175, 1999.

Capaldo, K. P., Pilinis, C., and Pandis, S. N.: A computationally efficient hybrid approach for dynamic gas/aerosol transfer in air quality models, Atmos. Environ., 34, 3617-3627, 2000.

Chameides, W. L., Luo, C., Salor, R., Streets, D., Huang, Y., Bergin, M., and Giorgi, F.: Correlation between model-calculated anthropogenic aerosols and satellite-derived cloud optical depths: Indication of indirect effect?, J. Geophys. Res., 107, 4085, doi:10.1029/2000JD000208, 2002.

Cheng, T., Peng, Y., Feichter, J., and Tegen, I.: An improvement on the dust emission scheme in the global aerosol-climate model ECHAM5-HAM, Atmos. Chem. Phys., 8, 1105-1117, doi:10.5194/acp-8-1105-2008, 2008.

Chervenkov, H. and Jakobs, H.: Dust storm simulation with regional air quality-Problems and results, Atmos. Environ., 45, 39653976, 2011. 
Choi, Y.-J. and Fernando, H. J. S.: Implementation of a windblown dust parameterization into MODELS-3/CMAQ: Application to episodic PM events in the US/Mexico border, Atmos. Environ., 42, 6039-6046, 2008.

Chou, M.-D. and Suarez, M. J.: An efficient thermal infrared radiation parameterization for use in general circulation models, NASA Tech. Memo NASA/TM-104606, 84 pp., 1994.

Clements, T., Merriam, T. H., Stone, R. O., Eimann, J. L., and Reade, H. L.: A study of desert surface conditions, Tech. Rep. EP-53, 130 pp., US Army, Natick Lab., Natick, Mass., 1957.

Crowley, J. N., Ammann, M., Cox, R. A., Hynes, R. G., Jenkin, M. E., Mellouki, A., Rossi, M. J., Troe, J., and Wallington, T. J.: Evaluated kinetic and photochemical data for atmospheric chemistry: Volume V - heterogeneous reactions on solid substrates, Atmos. Chem. Phys., 10, 9059-9223, doi:10.5194/acp-10-90592010, 2010.

Darmenova, K., Sokolik, I. N., Shao, Y., Marticorena, B., and Bergametti, G.: Development of a physically based dust emission module within the Weather Research and Forecasting (WRF) model: Assessment of dust emission parameterizations and input parameters for source regions in Central and East Asia, J. Geophys. Res., 114, D14201, doi:10.1029/2008JD011236, 2009.

Deeter, M. N., Emmons, L. K., Francis, G. L., Edwards, D. P., Gille, J. C., Warner, J. X., Khattatov, B., Ziskin, D., Lamarque, J.-F., Ho, S.-P., Yuding, V., Attie, J.-L., Packman, D., Chen, J., Mao, D., and Drummond, J. R.: Operational carbon monoxide retrieval algorithm and selected results for the MOPITT instrument, J. Geophys. Res., 108, 4399, doi:10.1029/2002JD003186, 2003.

Dentener, F. J., Carmichael, G. R., Zhang, Y., Lelieveld, J., and Crutzen, P. J.: Role of mineral aerosol as a reactive surface in the global troposphere, J. Geophys. Res., 101, 22869-22889, 1996.

Dudhia, J.: A multi-layer soil temperature model for MM5, the 6th Annual MM5 Users Workshop, Boulder, CO, USA, 22-24 July, 1996.

Fairlie, T. D., Jacob, D. J., and Park, R. J.: The impact of transpacific transport of mineral dust in the United States, Atmos. Environ., 41, 1251-1266, 2007.

Fairlie, T. D., Jacob, D. J., Dibb, J. E., Alexander, B., Avery, M. A., van Donkelaar, A., and Zhang, L.: Impact of mineral dust on nitrate, sulfate, and ozone in transpacific Asian pollution plumes, Atmos. Chem. Phys., 10, 3999-4012, doi:10.5194/acp-10-39992010, 2010.

Fécan, F., Marticorena, B., and Bergametti, G.: Parametrization of the increase of the aeolian erosion threshold wind friction velocity due to soil moisture for arid and semi-arid areas, Ann. Geophys., 17, 149-157, doi:10.1007/s00585-999-0149-7, 1999.

Fishman, J., Wozniak, A. E., and Creilson, J. K.: Global distribution of tropospheric ozone from satellite measurements using the empirically corrected tropospheric ozone residual technique: Identification of the regional aspects of air pollution, Atmos. Chem. Phys., 3, 893-907, doi:10.5194/acp-3-893-2003, 2003.

Fountoukis, C. and Nenes, A.: ISORROPIA II: a computationally efficient thermodynamic equilibrium model for $\mathrm{K}^{+}-\mathrm{Ca}^{2+}$. $\mathrm{Mg}^{2+}-\mathrm{NH}_{4}^{+}-\mathrm{SO}_{4}^{2-}-\mathrm{NO}_{3}^{-}-\mathrm{Cl}^{-}-\mathrm{H}_{2} \mathrm{O}$ aerosols, Atmos. Chem. Phys., 7, 4639-4659, doi:10.5194/acp-7-4639-2007, 2007.

Fountoukis, C., Nenes, A., Sullivan, A., Weber, R., Van Reken, T., Fischer, M., Matías, E., Moya, M., Farmer, D., and Cohen, R. C.: Thermodynamic characterization of Mexico City aerosol during MILAGRO 2006, Atmos. Chem. Phys., 9, 2141-2156, doi:10.5194/acp-9-2141-2009, 2009.

Ginox, P., Chin, M., Tegen, I., Prospero, J. M., Holben, B., Dubovik, O., and Lin, S.: Sources and distributions of dust aerosols simulated with the GOCART model, J. Geophys. Res., 106, 22055 22074, 2001.

Goodman, A. L., Underwood, G. M., and Grassian, V. H.: A laboratory study of the heterogeneous reaction of nitric acid on calcium carbonate particles, J. Geophys. Res., 105, 29053-29064, 2000.

Grell, G. A. and Dévényi, D.: A generalized approach to parameterizing convection combining ensemble and data assimilation techniques, Geophys. Res. Lett., 29, 1693, doi:10.1029/2002GL015311, 2002.

Hong, S. Y. and Lim, J.: The WRF Single Moment 6-class microphysics scheme (WSM6), Journal of the Korean Meteorological Society, 42, 129-151, 2006.

Hong, S. Y., Noh, Y., and Dudhia, J.: A new vertical diffusion package with explicit treatment of entrainment processes, Mon. Weather Rev., 134, 2318-2341, 2006.

IPCC: Climate Change 2007: The Physical Science Basis, Contribution of Working Group I to the Fourth Assessment Report of the Intergovernmental Panel on Climate Change, edited by: Solomon, S., Qin, D., Manning, M., Chen, Z., Marquis, M., Averyt, K. B., Tignor, M., and Miller, H. L., Cambridge University Press, Cambridge, United Kingdom and New York, NY, USA, 2007.

Jacobson, M. Z.: Studying the effects of calcium and magnesium on size-distributed nitrate and ammonium with EQUISOLV II, Atmos. Environ., 33, 3635-3649, 1999.

Jaffe, D. A., Snow, J., and Cooper, O.: The 2001 Asian dust events: Transport and impact on surface aerosol concentrations in the U.S., Eos, 84, 501-516, 2003.

Kang, J.-Y., Yoon, S.-C., Shao, Y., and Kim, S.-W.: Comparison of vertical dust flux by implementing three dust emission schemes in WRF/Chem, J. Geophys. Res., 116, D09202, doi:10.1029/2010JD014649, 2011.

Karydis, V. A., Tsimpidi, A. P., Fountoukis, C., Nenes, A., Zavala, M., Lei, W., Molina, L. T., and Pandis, S. N.: Simulating the fine and coarse inorganic particulate matter concentrations in a polluted megacity, Atmos. Environ., 44, 608-620, 2010.

Karydis, V. A., Kumar, P., Barahona, D., Sokolik, I. N., and Nenes, A.: On the effect of insoluble dust particles on global $\mathrm{CCN}$ and droplet number, J. Geoph. Res., 116, D23204, doi:10.1029/2011JD016283, 2011.

Kawamura, R.: Study of sand movement by wind, Hydraul. Eng. Lab. Tech. Rep., HEL-2-8, Univ. of Calif., Berkeley, USA, 99$108,1964$.

Knippertz, P. and Todd, M. C.: Mineral dust aerosols over the Sahara: Meteorological controls on emission and transport and implications for modeling, Rev. Geophys., 50, RG1007, doi:10.1029/2011RG000362, 2012.

Knipping, E. M. and Dabdub, D.: Modeling surface-mediated renoxification of the atmosphere via reaction of gaseous nitric oxide with deposited nitric acid, Atmos. Environ., 36, 57415748, 2002.

Kursinski, E. R., Bennett, R. A., Gochis, D., Gutman, S. I., Holub, K. L., Mastaler, R., Minjarez Sosa, C., Minjarez Sosa, I., and van Hove, T.: Water vapor and surface observations in northwestern Mexico during the 2004 NAME Enhanced Observing Period, Geophys. Res. Lett., 35, L03815, doi:10.1029/2007GL031404, 
2008.

Laurent, B., Marticorena, B., Bergametti, G., and Mei, F.: Modeling mineral dust emissions from Chinese and Mongolian deserts, Global Planet. Change, 52, 121-141, 2006.

Li, L., Chen, Z. M., Zhang, Y. H., Zhu, T., Li, J. L., and Ding, J.: Kinetics and mechanism of heterogeneous oxidation of sulfur dioxide by ozone on surface of calcium carbonate, Atmos. Chem. Phys., 6, 2453-2464, doi:10.5194/acp-6-2453-2006, 2006.

Li, H. J., Zhu, T., Zhao, D. F., Zhang, Z. F., and Chen, Z. M.: Kinetics and mechanisms of heterogeneous reaction of $\mathrm{NO}_{2}$ on $\mathrm{CaCO}_{3}$ surfaces under dry and wet conditions, Atmos. Chem. Phys., 10, 463-474, doi:10.5194/acp-10-463-2010, 2010.

Liao, H. and Seinfeld, J. H.: Global impacts of gas-phase chemistryaerosol interactions on direct radiative forcing by anthropogenic aerosols and ozone, J. Geophys. Res., 110, D18208, doi:10.1029/2005JD005907, 2005.

Liu, M. and Westphal, D. L.: A study of the sensitivity of simulated mineral dust production to model resolution, J. Geophys. Res., 106, 18099-18112, 2001.

Liu, M., Westphal, D. L., Wang, S., Shimizu, A., Sugimoto, N., Zhou, J., and Chen, Y.: A high-resolution numerical study of the Asian dust storms of April 2001, J. Geophys. Res., 108, 8653, doi:10.1029/2002JD003178, 2003.

Mahowald, N., Kohfeld, K., Hansson, M., Balkanski, Y., Harrison, S. P., Printice, I. C., Schulz, M., and Rodhe, H.: Dust sources and deposition during the last glacial maximum and current climate: A comparison of model results with paleodata from ice cores and marine sediments, J. Geophys. Res., 104, 15895-15916, 1999.

Manktelow, P. T., Carslaw, K. S., Mann, G. W., and Spracklen, D. V.: The impact of dust on sulfate aerosol, $\mathrm{CN}$ and $\mathrm{CCN}$ during an East Asian dust storm, Atmos. Chem. Phys., 10, 365-382, doi:10.5194/acp-10-365-2010, 2010.

Marticorena, B. and Bergametti, G.: Modeling the atmospheric dust cycle: 1. Design of a soil-derived dust emission scheme, J. Geophys. Res., 100, 16415-16430, 1995.

Marticorena, B., Bergamettie, G., Aumont, B., Callot, Y., N'Doume, C., and Legrand, M.: Modeling the atmospheric dust cycle: 2. Simulation of Saharan dust sources, J. Geophys. Res., 102, 4387-4404, 1997.

McNaughton, C. S., Clarke, A. D., Kapustin, V., Shinozuka, Y., Howell, S. G., Anderson, B. E., Winstead, E., Dibb, J., Scheuer, E., Cohen, R. C., Wooldridge, P., Perring, A., Huey, L. G., Kim, S., Jimenez, J. L., Dunlea, E. J., DeCarlo, P. F., Wennberg, P. O., Crounse, J. D., Weinheimer, A. J., and Flocke, F.: Observations of heterogeneous reactions between Asian pollution and mineral dust over the Eastern North Pacific during INTEX-B, Atmos. Chem. Phys., 9, 8283-8308, doi:10.5194/acp-9-8283-2009, 2009.

Michel, A. E., Usher, C. R., and Grassian, V. H.: Heterogeneous and catalytic uptake of ozone on mineral oxides and dusts: A Knudsen cell investigation, Geophys. Res. Lett., 29, 1665, doi:10.1029/2002GL014896, 2002.

Mlawer, E. J., Taubman, S. J., Brown, P. D., Iacono, M. J., and Clough, S. A.: Radiative transfer for inhomogeneous atmospheres: RRTM, a validated correlated-k model for the longwave, J. Geophys. Res., 102, 16663-16682, 1997.

Moya, M., Pandis, S. N., and Jacobson, M. Z.: Is the size distribution of urban aerosols determined by thermodynamic equilibrium?: An application to Southern California, Atmos. Environ.,
36, 2349-2365, 2002.

Midwest Research Institute: Analysis of fine fraction of particulate matter in fugitive dust, Report to the WRAP by Midwest Research Institut, Project No. 110397, 2005.

Ndour, M., D’Anna, B., George, C., Ka, O., Balkanski, Y., Kleffmann, J., Stemmler, K., and Ammann, M.: Photoenhanced uptake of $\mathrm{NO}_{2}$ on mineral dust: Laboratory experiments and model simulations, Geophys. Res. Lett., 35, L05812, doi:10.1029/2007GL032006, 2008.

Ndour, M., Conchon, P., D’Anna, B., Ka, O., and George, C.: Photochemistry of mineral dust surface as a potential atmospheric renoxification process, Geophys. Res. Lett., 36, L05816, doi:10.1029/2008GL036662, 2009.

Nenes, A., Pilinis, C., and Pandis S. N.: ISORROPIA: a new thermodynamic equilibrium model for multiphase multicomponent marine aerosols, Aquatic Geochemistry, 4, 123-152, 1998.

Nenes, A., Pilinis, C., and Pandis, S. N.: Continued development and testing of a new thermodynamic aerosol module for urban and regional air quality models. Atmos. Environ., 33, 15531560, 1999.

Nickovic, S., Kallos, G., Papadopoulos, A., and Kakaliagou, O.: A model for prediction of desert dust cycle in the atmosphere, J. Geophys. Res., 106, 18113-18129, doi:10.1029/2000JD900794, 2001.

Nowottnick, E., Colarco, P., Ferrare, R., Chen, G., Ismail, S., Anderson, B., and Browell, E.: Online simulations of mineral dust aerosol distributions: Comparisons to NAMMA observations and sensitivity to dust emission parameterization, J. Geophys. Res., 115, D03202, doi:10.1029/2009JD012692, 2010.

Park, R. J., Jacob, D. J., Field, B. D., Yantosca, R. M., and Chin, M.: Natural and trans-boundary pollution influences on sulfate-nitrate-ammonium aerosols in the United States: implications for policy, J. Geophys. Res., 109, D15204, doi:10.1029/2003JD004473, 2004.

Pilinis, C., Capaldo, K. P., Nenes, A., and Pandis, S. N.: MADM-A new multicomponent aerosol dynamic model, Aerosol Sci. Tech., 32, 482-502, 2000.

Pozzoli, L., Bey, I., Rast, S., Schultz, M. G., Stier, P., and Feichter, J.: Trace gas and aerosol interactions in the fully coupled model of aerosol-chemistry-climate ECHAM5HAMMOZ: 1. Model description and insights from the spring 2001 TRACE-P experiment, J. Geophys. Res., 113, D07308, doi:10.1029/2007JD009007, 2008a.

Pozzoli, L., Bey, I., Rast, S., Schultz, M. G., Stier, P., and Feichter, J.: Trace gas and aerosol interactions in the fully coupled model of aerosol-chemistry-climate ECHAM5-HAMMOZ: 2. Impact of heterogeneous chemistry on the global aerosol distributions, J. Geophys. Res., 113, D07309, doi:10.1029/2007JD009008, 2008b.

Prospero, J. M., Ginoux, P., Torres, O., Nicholson, S. E., and Gill, T. E.: Environmental characterization of global sources of atmospheric soil dust identified with the nimbus 7 total ozone mapping spectrometer (TOMS) absorbing aerosol product, Rev. Geophys., 40, 1002, doi:10.1029/2000RG000095, 2002.

Remer, L. A., Kaufman, Y. J., Tanre, D., Mattoo, S., Chu, D. A., Martins, J. V., Li, R.-R., Ichoku, C., Levy, R. C., Kleidman, R. G., Eck, T. F., Vermote, E., and Holben, B. N.: The MODIS aerosol algorithm, products, and validation, J. Atmos., Sci., 62, 947-973, 2005. 
Rivera-Figueroa, A. M., Sumner, A. L., and Finlayson-Pitts, B. J.: Laboratory studies of potential mechanisms of renoxification of tropospheric nitric acid, Environ. Sci. Technol., 37, 548-554, 2003.

Roselle, S. J., Appel, K. W., Foley, K. M., Bhave, P. V., Pleim, J. E., Mathur, R., Otte, T. L., Gilliam, R. C., Sarwar, G., Nolte, C. G., Gililand, A. B., Pinder, R. W., and Swall, J. L.: Incremental testing of updates to the Community Multiscale Air Quality (CMAQ) modeling system version 4.7 , the $7^{\text {th }}$ Annual CMAS conference, Chapel Hill, NC, USA, 6-8 October, 2008.

Roy, B., Mathur, R., Gilliland, A. B., and Howard, S. C.: A comparison of CMAQ-based aerosol properties with IMPROVE, MODIS, and AERONET data, J. Geophys. Res., 112, D14301, doi:10.1029/2006JD008085, 2007.

Satheesh, S. K. and Moorthy, K. K.: Radiative effects of natural aerosols: A review, Atmos. Environ., 39, 2089-2110, 2005.

Schwartz, S. E.: Mass-transport considerations pertinent to aqueous phase reactions of gases in liquid-water clouds, in: Chemistry of Multiphase Atmospheric System, NATO ASI Ser., Ser. G: Ecol. Sci., vol. 6, edited by: Jaeschke, W., Springer-Verlag, New York, USA, 415-471, 1986.

Seinfeld, J. H. and Pandis, S. N.: Atmospheric Chemistry and Physics: From Air Pollution to Climate Change, 2nd ed., Wiley, New York, USA, 2006.

Shao, Y.: A model for mineral dust emission, J. Geophys. Res., 106, 20239-20254, 2001.

Shao, Y. and Dong, C. H.: A review on East Asian dust storm climate, modelling and monitoring, Global Planet. Change 52, 122, doi:10.1016/j.gloplacha.2006.02.011, 2006.

Shao, Y., Fink, A. H., and Klose, M.: Numerical simulation of a continental-scale Saharan dust event, J. Geophys. Res., 115, D13205, doi:10.1029/2009JD012678, 2010.

Solomos, S., Kallos, G., Kushta, J., Astitha, M., Tremback, C., Nenes, A., and Levin, Z.: An integrated modeling study on the effects of mineral dust and sea salt particles on clouds and precipitation, Atmos. Chem. Phys., 11, 873-892, doi:10.5194/acp11-873-2011, 2011.

Song, C. H., Kim, C. M., Lee, Y. J., Carmichael, G. R., Lee, B. K., and Lee, D. S.: An evaluation of reaction probabilities of sulfate and nitrate precursors onto East Asian dust particles, J. Geophys. Res., 112, D18206, doi:10.1029/2006JD008092, 2007.

Spyrou, C., Mitsakou, C., Kallos, G., Louka, P., and Vlastou, G.: An improved limited area model for describing the dust cycle in the atmosphere, J. Geophys. Res., 115, D17211, doi:10.1029/2009JD013682, 2010.

Streets, D. G., Bond, T. C., and Carmichael, G. R.: An inventory of gaseous and primary aerosol emissions in Asia in the year 2000, J. Geophys. Res., 108, 8809, doi:10.1029/2002JD003093, 2003.

Tanaka, T.: Global dust budget, in: Encyclopedia of Earth, edited by: Hanson, H., Environmental Information Coalition, National Council for Science and the Environment, Washington DC, USA, 2007.

Tang, Y., Carmichael, G. R., Kurata, G., Uno, I., Weber, R. J., Song, C.-H., Guttikunda, S. K., Woo, J.-H., Streets, D. G., Wei, C., Clarke, A. D., Huebert, B., and Anderson, T. L.: Impacts of dust on regional tropospheric chemistry during the ACE-Asia experiment: A model study with observations, J. Geophys. Res., 109, D19S21, doi:10.1029/2003JD003806, 2004.
Tang, M. J., Thieser, J., Schuster, G., and Crowley, J. N.: Uptake of $\mathrm{NO}_{3}$ and $\mathrm{N}_{2} \mathrm{O}_{5}$ to Saharan dust, ambient urban aerosol and soot: a relative rate study, Atmos. Chem. Phys., 10, 2965-2974, doi:10.5194/acp-10-2965-2010, 2010.

Tegen, I. and Fung, I.: Modeling of mineral dust in the atmosphere: Source, transport, and optical thickness, J. Geophys. Res., 99, 22897-22914, 1994.

Tie, X., Madronich, S., Walters, S., Edwards, D. P., Ginoux, P., Mahowald, N., Zhang, R., Lou, C., and Brasseur, G.: Assessment of the global impact of aerosols on tropospheric oxidants, J. Geophys. Res., 110, D03204, doi:10.1029/2004JD005359, 2005.

Underwood, G. M., Song, C. H., Phadnis, M., Carmichael, G. R., and Grassian, V. H.: Heterogeneous reactions of $\mathrm{NO}_{2}$ and $\mathrm{HNO}_{3}$ on oxides and mineral dust: A combined laboratory and modeling study, J. Geophys. Res., 106, 18055-18066, 2001.

Uno, I., Carmichael, G. R., Streets, D. G., Tang Y., Yienger, J. J., Satake, S., Wang, Z., Woo, J.-H., Guttikunda, S., Uematsu, M., Matsumoto, K., Tanimoto, H., Yoshioka, K., and Iida, T.: Regional chemical weather forecasting system CFORS: Model descriptions and analysis of surface observations at Japanese island stations during the ACE-Asia experiment, J. Geophys. Res., 108, 8668, doi:10.1029/2002JD002845, 2003.

Uno, I., Wang, Z., Chiba, M., Chun, Y. S., Gong, S. L., Hara, Y., Jung, E., Lee, S.-S., Liu, M., Mikami, M., Music, S., Nickovic, S., Satake, S., Shao, Y., Song, Z., Sugimoto, N., Tanaka, T., and Westphal, D. L.: Dust model intercomparison (DMIP) study over Asia: Overview, J. Geophys. Res., 111, D12213, doi:10.1029/2005JD006575, 2006.

Van Pelt, R. S. and Zobeck, T. M.: Chemical constituents of fugitive dust, Environ. Monit. Assess., 130, 3-16, doi:10.1007/s10661006-9446-8, 2007.

Wagner, C., Hanisch, F., Holmes, N., de Coninck, H., Schuster, G., and Crowley, J. N.: The interaction of $\mathrm{N}_{2} \mathrm{O}_{5}$ with mineral dust: aerosol flow tube and Knudsen reactor studies, Atmos. Chem. Phys., 8, 91-109, doi:10.5194/acp-8-91-2008, 2008.

Wang, K.: Multiscale multi-pollutant air quality modeling: Incorporation of dust treatments into CMAQ and application for criteria and hazardous air pollutants, Ph.D. thesis, North Carolina State University, Raleigh, NC, USA, 342 pp., 2011.

Wang, K. and Zhang, Y.: Development of an online dust module in CMAQ and its application to simulate the trans-Pacific transport of Asian dust, the International Symposium on Asian Dust/Aerosol and its Impact on Global Climate Change, Shanghai, China, 8-10 August, 2010.

Wang, K., Zhang, Y., Jacobson, M. Z., Liang, J.-Y., and Magliano, K.: A Study of gas/particle partitioning using inorganic thermodynamic equilibrium modules and data from the California Regional $\mathrm{PM}_{10} / \mathrm{PM}_{2.5}$ Air Quality Study, the Workshop on Agricultural Air Quality: State of the Science, Potomac, MD, USA, 5-8 June, 2006.

Wang, K., Zhang, Y., Jang, C., Phillips, S., and Wang, B.: Modeling intercontinental air pollution transport over the transPacific Region in 2001 using Community Multiscale Air Quality modeling system, J. Geophys. Res., 114, D04307, doi:10.1029/2008JD010807, 2009.

Westphal, D. L., Toon, O. B., and Carlson, T. N.: A two-dimensional numerical investigation of the dynamics and microphysics of Saharan dust storms, J. Geophys. Res., 92, 3027-3049, 1987. 
White, B. R.: Soil transport by winds on Mars, J. Geophys. Res., 84, 4643-4651, 1979.

Yang, X., Zhang, K., Jia, B., and Ci, L.: Desertification assessment in China: An overview, J. Arid Environ., 63, 517-531, 2005.

Yarwood, G., Rao, S., Yocke, M., and Whitten, G. Z.: Updates to the carbon bond mechanism: CB05, Report to the U.S. Environmental Protection Agency, RT-04-00675, 2005.

Yue, X., Wang, H., Wang, Z., and Fan, K.: Simulation of dust aerosol radiative feedback using the Global Transport Model of Dust: 1. Dust cycle and validation, J. Geophys. Res., 114, D10202, doi:10.1029/2008JD010995, 2009.

Zender, C. S., Bian, H., and Newman, D.: Mineral Dust Entrainment and Deposition (DEAD) model: Description and 1990s dust climatology, J. Geophys. Res., 108, 4416, doi:10.1029/2002JD002775, 2003.

Zhang, K. M., Knipping, E. M., Wexler, A. S., Bhave, P. V., and Tonnesen, G. S.: Size distribution of sea-salt emissions as a function of relative humidity, Atmos. Environ., 39, 3373-3379, 2005.

Zhang, Y. and Carmichael, G. R.: The role of mineral aerosol in tropospheric chemistry in East Asia - a model study, J. Appl. Meteor., 38, 353-366, 1999.
Zhang, Y., Sunwoo, Y., Kotamarthi, V., and Carmichael, G. R.: Photochemical oxidant processes in the presence of dust: An evaluation of the impact of dust on particulate nitrate and ozone formation, J. Appl. Meteor., 33, 813-824, 1994.

Zhang, Y., Liu, P., Pun, B., and Seigneur, C.: A comprehensive performance evaluation of MM5-CMAQ for the summer 1999 Southern Oxidants Study episode-Part I: Evaluation protocols, databases, and meteorological predictions, Atmos. Environ., 40, 4825-4838, 2006.

Zhang, Y., Vijayaraghavan, K., Wen, X.-Y., Snell, H. E., and Jacobson, M. Z.: Probing into regional $\mathrm{O}_{3}$ and PM pollution in the U.S., Part I: A 1-year CMAQ simulation and evaluation using surface and satellite data, J. Geophys. Res., 114, D22304, doi:10.1029/2009JD011898, 2009.

Zhang, Y., Cheng, S.-H., Chen, Y.-S., and Wang, W.-X.: Application of MM5 in China: Model evaluation, seasonal variations, and sensitivity to horizontal grid resolutions, Atmos. Environ., 45, 3454-3465, 2011.

Zhu, S., Butler, T., Sander, R., Ma, J., and Lawrence, M. G.: Impact of dust on tropospheric chemistry over polluted regions: a case study of the Beijing megacity, Atmos. Chem. Phys., 10, 38553873, doi:10.5194/acp-10-3855-2010, 2010. 